Review

\title{
Large-Scale Synthesis of Carbon Nanomaterials by Catalytic Chemical Vapor Deposition: A Review of the Effects of Synthesis Parameters and Magnetic Properties
}

\author{
Xiaosi Qi ${ }^{1}$, Chuan Qin ${ }^{1}$, Wei Zhong ${ }^{1, *}$, Chaktong Au ${ }^{2, *}$, Xiaojuan Ye ${ }^{1}$ and Youwei Du ${ }^{1}$ \\ 1 Nanjing National Laboratory of Microstructures and Jiangsu Provincial Laboratory for \\ NanoTechnology, Nanjing University, Nanjing 210093, China; \\ E-Mails: xiaosi6460099@yahoo.com.cn (X.S.Q.); icecat1988@gmail.com (C.Q.); \\ 1csyxj@163.com (X.J.Y.); dyw@nju.edu.cn (Y.W.D.) \\ 2 Chemistry Department, Hong Kong Baptist University, Hong Kong, China \\ * Authors to whom correspondence should be addressed; E-Mails: wzhong@nju.edu.cn (W.Z.); \\ pctau@hkbu.edu.hk (C.T.A.); Tel.: +86-25-83621200; Fax: +86-25-83595535.
}

Received: 26 June 2010 / Accepted: 26 July 2010 / Published: 30 July 2010

\begin{abstract}
The large-scale production of carbon nanomaterials by catalytic chemical vapor deposition is reviewed in context with their microwave absorbing ability. Factors that influence the growth as well as the magnetic properties of the carbon nanomaterials are discussed.
\end{abstract}

Keywords: carbon nanomaterials; catalytic chemical vapor deposition; magnetic properties; microwave absorbing ability

\section{Introduction}

Since the landmark paper of Ijima [1], carbon nanotubes (CNTs) have been studied widely [2-4]. The unique physical and chemical properties of CNTs suggests that the materials can potentially be utilized in areas such as field emission display [5], microelectronic devices [6-12], hydrogen storage [13] and composite material additives [14]. Generally, CNTs can be divided into two categories: single-walled nanotubes (SWNTs) [15] and multi-walled nanotubes (MWNTs) [16]. The molecular structure of SWNTs can be visualized as graphene sheets that roll up in a particular direction as designated by a pair of integers (Figure 1) [16,17]. Because of the quasi one-dimensional (1D) 
structure, SWNTs display unusual mechanical, electrical, optical, chemical and thermal properties [18-22] that are ideal for nano-electronic devices such as quantum wires [23], single electron transistors [24] field-effect transistors and sensors [25,26]. In the past two decades, SWNTs were synthesized by laser ablation [27] or arc discharge method [28]. For the fabrication of SWNT-based devices, the as-synthesized SWNTs have to be purified and then suspended in an organic solvent for final deposition onto a selected substrate. One can envisage that precision control on the orientation of SWNTs for device integration is difficult. When one comes to commercialization, one has to produce pure and well-defined SWNTs in low cost. If one wants to adopt the existing processes in semiconductor industries for SWNT production, a route with temperature much lower than that of laser ablation and arc discharge is required [29]. One of the approaches that can satisfy such a requirement is chemical vapor deposition (CVD).

Figure 1. (a) Formation of single-walled nanotubes (SWNTs) by rolling a graphene sheet along a chiral vector c [17] and (b) Transmission electron microscopy (TEM) and Scanning electron microscopy (SEM) (inset) micrographs of SWNTs grown on Ag [15].
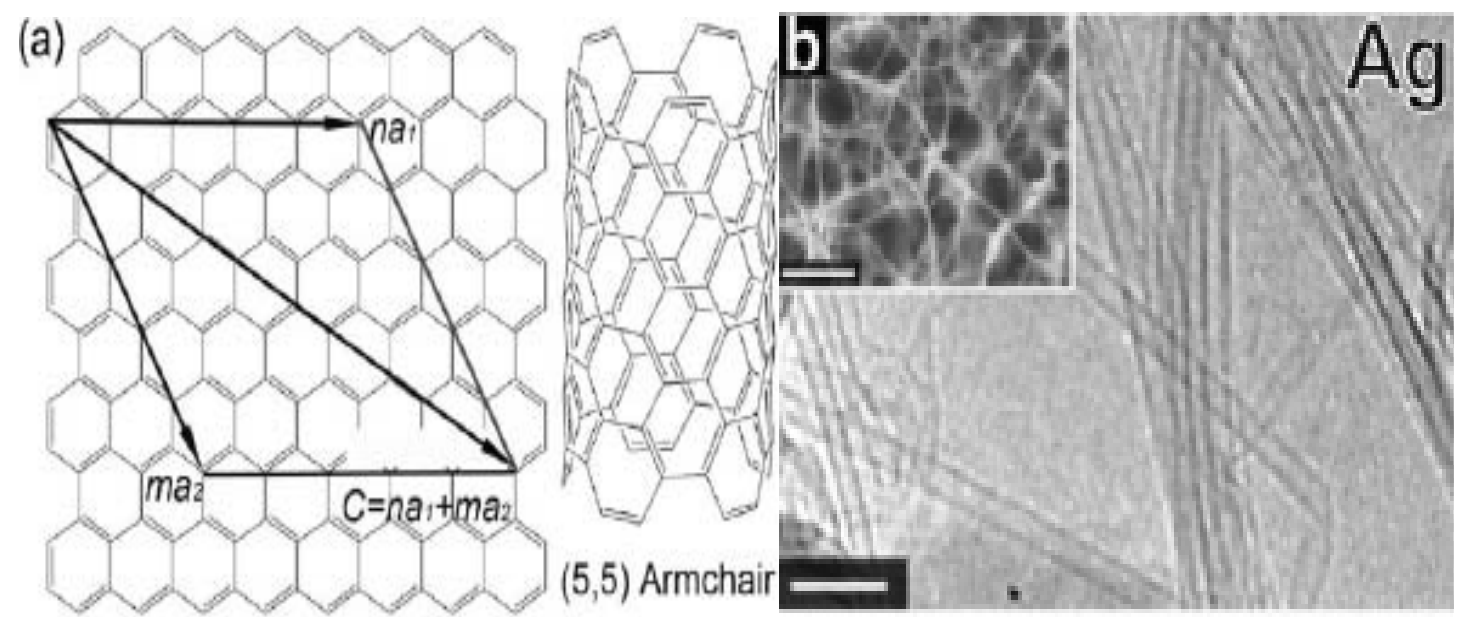

Similarly, MWNTs can be considered as a stack of graphene sheets that roll up into concentric cylinders (Figure 2a), with each wall layer (a graphite basal plane) parallel to the central axis $(\theta=0)$ (Figure 2b). When the angle between the graphite basal planes and the tube axis is nonzero, stacked-cone structures similar to that of bamboo or piled cone result (Figure 2c) [30]. 
Figure 2. (a) Formation of multi-walled nanotubes (MWNT) by rolling up a stack of graphene sheets into concentric cylinders; straight MWNTs (b) $\theta=0$ and (c) $\theta \neq 0 \quad$ [30].
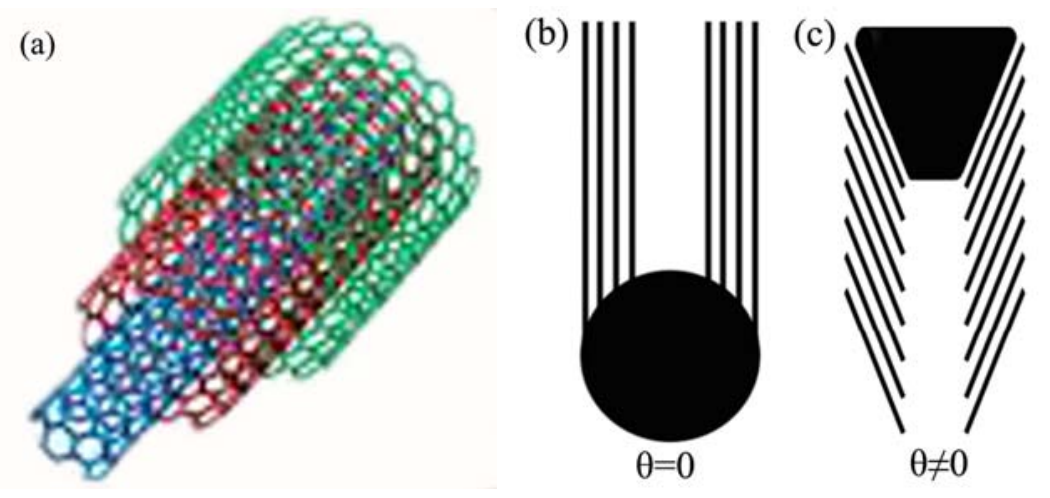

Moreover, due to the existence of hexagonal, pentagonal and heptagonal carbon rings, CNTs with shapes unlike that of straight CNTs, such as helical carbon nanotubes (HCNTs) [31] and carbon nanocoils (CNCs) [32], are formed. A HCNT is constructed by periodically introducing heptagonal and pentagonal rings into the hexagonal network of the graphene layers along the tube axis [33]. Unlike the linear carbon nanofibers (CNFs) and CNTs, HCNTs (Figure 3a) and CNCs (Figure 3b) [34] are chiral materials. If an electrical current passes through a HCNT or CNC, there is the generation of an inductive magnetic field. Therefore, HCNTs and CNCs are potentially applicable in the fabrication of electromagnetic nanoswitches and nanotransformers. In addition, micro/nano carbon coils have the potential of being used as nanosprings [35], micro-antenna, bio-activators or bio-deactivators, energy converters [36], micro-sensors [37], etc.

Figure 3. (a) TEM image of helical carbon nanotubes (HCNTs) and (b) FE-SEM image of double carbon nanocoils (CNCs) [34].

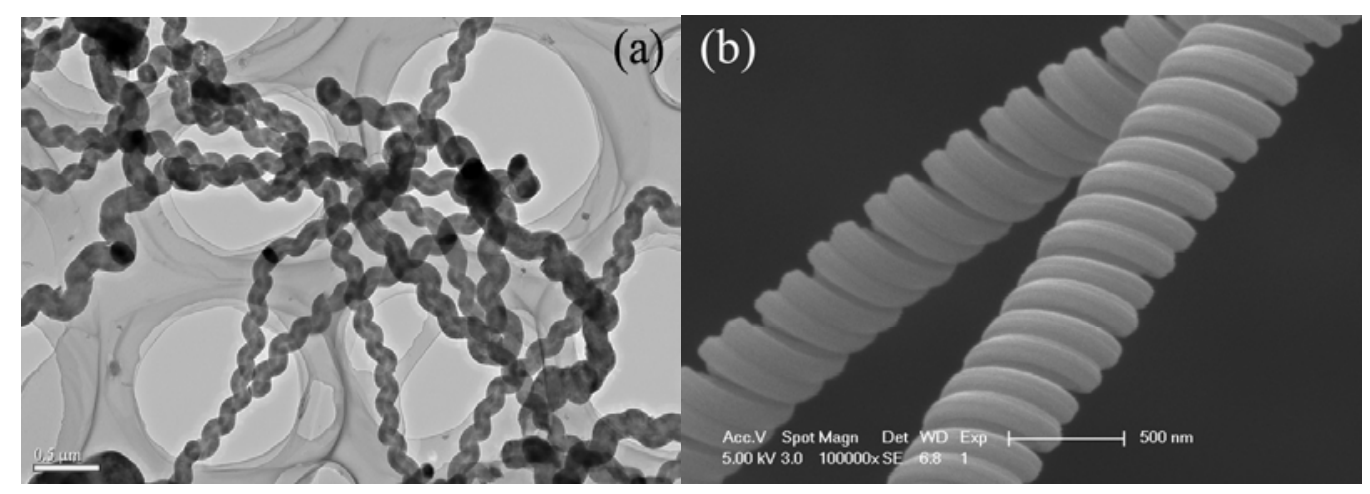

Depending on where the pentagonal and heptagonal rings are placed, HCNTs can be metallic, semiconducting or semi-metallic, which is impossible for the straight CNTs [38]. In arc-discharge and laser ablation processes, straight CNTs are formed owing to the high temperature (required for graphite vaporization) and the high mobility of carbon atoms. However, in CVD processes, CNTs with straight or curved morphologies are often formed simultaneously. For example, HCNTs or CNCs were reported as by-product by Ivanov et al. in the synthesis of CNTs by means of CVD [39]. In the past 20 years, efforts have been put in to synthesize HCNTs and CNCs selectively [39-50]. The texture of 
catalytically grown CNCs [41] and the growth mechanism of HCNTs [42] were studied. By optimizing experimental parameters [45,49] and using specific catalysts [46-50], one can enhance the selectivity to HCNTs or CNCs. Hou et al. [46] reported the synthesis of HCNTs in the co-pyrolysis of $\mathrm{Fe}(\mathrm{CO})_{5}$ (as floating catalyst precursor) and pyridine or toluene (as carbon source) in $\mathrm{H}_{2}$ at temperatures above $1000{ }^{\circ} \mathrm{C}$. Luo et al. [51] synthesized HCNTs as major products in the thermal reduction of ethyl ether over $\mathrm{Zn}$ in a stainless-steel autoclave at $700{ }^{\circ} \mathrm{C}$. Bajpai et al. [44] synthesized perpendicularly aligned HCNTs by the co-pyrolysis of $\mathrm{Fe}(\mathrm{CO})_{5}$ and pyridine in a mixed flow of $\mathrm{Ar}$ and $\mathrm{H}_{2}$ at temperatures ranging from 900 to $1100{ }^{\circ} \mathrm{C}$. Motojima and co-workers [52,53] synthesized double-helix CNCs over nickel through a high-temperature route, and reported that the $\mathrm{Ni}$ particles were often located at the tips of the CNCs. Pan et al. [54] showed that the uneven speed of carbon extrusion at different parts of the catalyst grains led to the helical growth of coils.

In terms of upward scalability, cost, and synthesis temperature, the CVD method is superior to arc discharge and laser ablation. The plasma-enhanced CVD (PECVD) method can be used to synthesize carbon nanomaterials in large scale. An advantage of using the PECVD approach is that the as-synthesized products are almost totally deposited on the substrate and are easy to collect. At present, this is the only technique that allows size, alignment and orientation control of nanospecies [55]. The plasmas used to decompose and activate the reactants in the gas phase are usually generated by hot filaments (HF) or by electrical discharges at different frequencies (DC, RF, and MW). The schematic of a typical PECVD set-up is shown in Figure 4 [30]. In PECVD synthesis, the catalyst powder was generally loaded on a substrate by means of wet chemistry or sputtering, usually accompanied by either chemical etching or thermal annealing to induce the formation of catalyst particles on the substrate. During synthesis, the substrate was kept at temperatures in the range of $650-1500{ }^{\circ} \mathrm{C}$, and reactant gas was introduced into the reactor with a pressure typically below 100 Torr. Moreover, the catalysis could be homogeneous in PECVD processes. For example, a metallorganic compound (e.g., ferrocene) was introduced into the reactor and decomposed by the plasma, directly providing metallic clusters in the gas phase [30].

Figure 4. Schematic of a typical plasma-enhanced chemical vapor deposition (PECVD) setup [30].

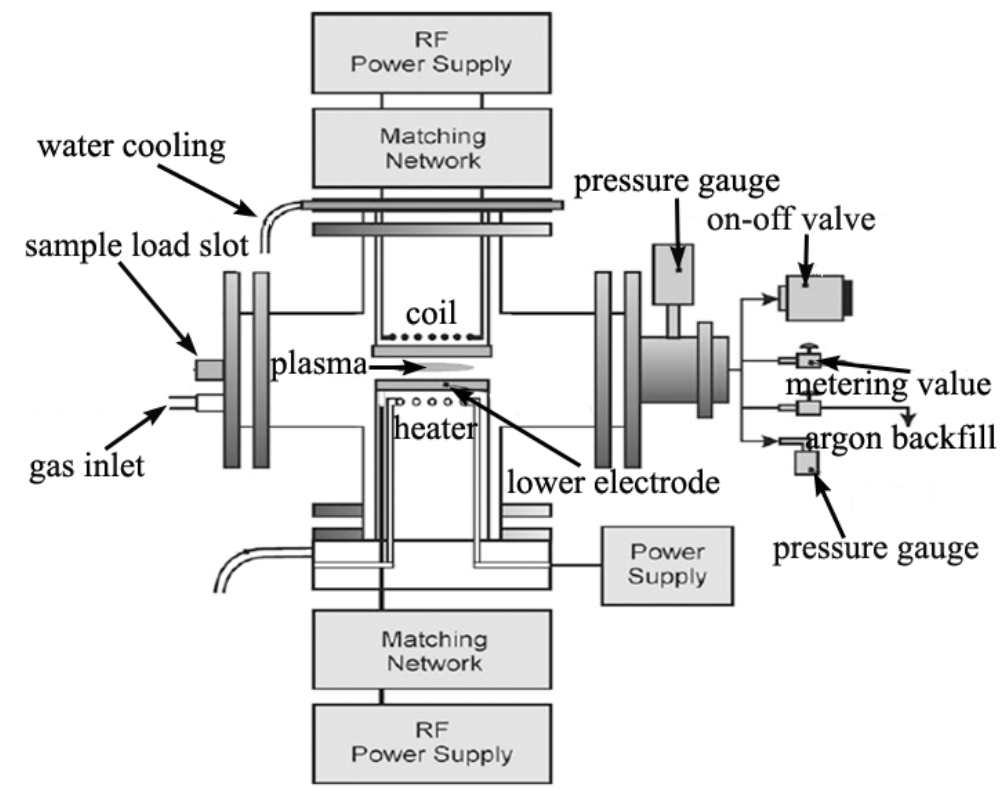


Nanomaterials can also be synthesized by means of thermal CVD. The method makes use of a flow reactor (quartz tube or stainless steel tube) placed inside a furnace for the pyrolysis of carbon-containing molecules. As reactants, carbon-rich gases mixed with argon or nitrogen flows are used, but sometimes the reactant can be in the form of liquid that is subsequently vaporized. If a catalyst is involved, the method is called catalytic CVD (CCVD). The catalyst can be either in powder form driven into the reactor together with the feed gases or previously coated or supported on a substrate. It is known that interesting and novel processes can occur under high-pressure conditions. Nevertheless, atmospheric pressure is often adopted for easy management. Compared to the PECVD method, the CCVD method has higher scalability but poorer control in deposition area. It is known that large-scale generation of a material is a critical factor for commercialization. Thus, wide utilization of carbon nanomaterials depends on whether they can be produced in large scale efficiently. As indicated by many studies [44,46,51], the CCVD approach is suitable for large-scale production of carbon nanomaterials.

In Figure 5, the schematic of a typical thermal CVD apparatus is shown. By means of catalytic decomposition of hydrocarbons, magnetic materials can be encapsulated inside carbon nanomaterials. There are potential applications of carbon nanospecies that are decorated with magnetic materials. For example, magnetic CNTs in the form of capsules or nanosubmarines can be used in the delivery of drugs to a desired location of a human body [56] and magnetic HCNTs can be used as a good microwave-absorbing material [57]. Generally speaking, the morphology and quality of the as-synthesized carbon species depend on factors such as (i) selection of catalyst and carbon source, (ii) temperature for the reduction of catalyst precursor, (iii) temperature for the pyrolysis of carbon source, (iv) nature of catalyst support, and (v) impurity in catalyst. Currently, the carbon sources for CCVD studies are acetylene, methane, carbon monoxide, ethylene, alcohols, toluene, pyridine, etc. After much research works, scientists find that carbon nanomaterials such as carbon nanospheres (CNPs), carbon nanobelts (CNBs), carbon nanorods (CNRs) can also be synthesized in CCVD processes by regulating the reaction parameters, giving good control in the morphology, scale, and selectivity of a desired product. In this article, we review the parameters that affect the quality of carbon nanospecies synthesized in CCVD processes, making emphasis on the mass production of carbon nanomaterials of different structures.

Figure 5. Schematic of a typical thermal CVD apparatus.

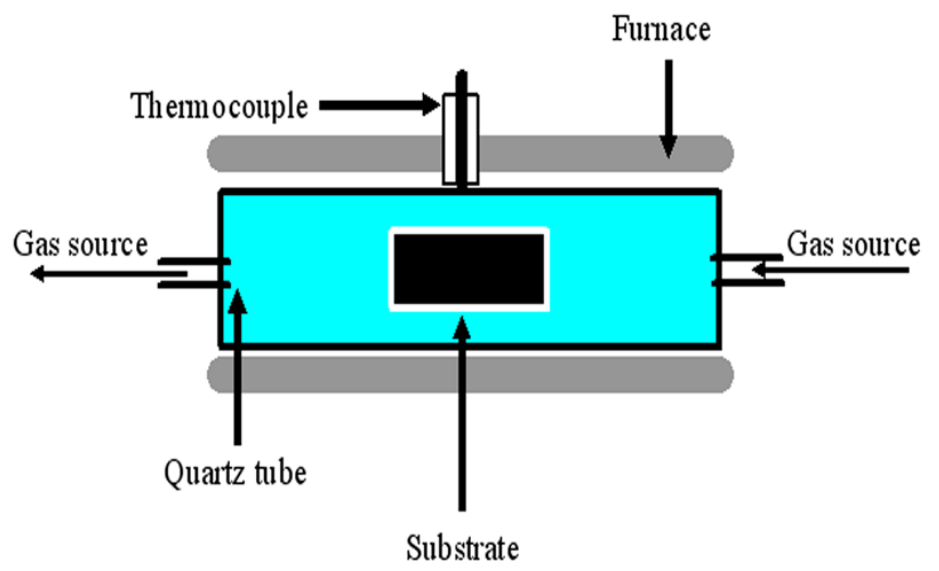




\section{Results and Discussion}

\subsection{Effect of Reactor Setup}

As shown in Figure 5, a typical thermal CVD setup for the synthesis of carbon nanomaterials consists of a reactor, gas source, thermocouple, tube furnace and substrate (where the catalyst is located). Commonly, a reactor is made of quartz or stainless steel in the form of a tube. It was noted that CVD reactivity inside a stainless steel reactor could be significantly different from that inside a quartz one. For example, a higher yield was observed in the former [58], whereas better selectivity was observed in the latter [59]. These differences are understandable, because iron is the major element in stainless steels, and elements such as $\mathrm{Fe}, \mathrm{Co}$, Ni and their alloys are known catalysts in CCVD processes. It is apparent that the iron in stainless steels has a positive effect on the product yield. Similar phenomena were observed by us [57,60]. Using a stainless steel tube, we found that the product of acetylene pyrolysis over Fe nanoparticles at $450{ }^{\circ} \mathrm{C}$ was helical carbon nanofibers (HCNFs) (1.582 g, mass of product collected after reaction) [60]. As shown in Figure 6, the HCNFs have two coiled nanofibers grown on a catalyst nanoparticle. The two coils are identical in cycle number and are almost equal in diameter, length, and pitch; the coiling direction, however, is opposite. In a quartz tube with the other factors kept unchanged, we observed that the product is HCNTs (85\% selectivity) and in much lower quantity $(0.413 \mathrm{~g}$ ) (Figure $7 \mathrm{a})$. As shown in Figure $7 \mathrm{~b}$, the HCNTs have two coiled nanotubes grown on a catalyst nanoparticle. The two tubes are mirror images to each other and are coiled in a regular and tight fashion with very short coil pitches [57].

Figure 6. Typical (a) TEM and (b) FE-SEM image of helical carbon nanofibers (HCNFs) synthesized in a stainless steel reactor over $\mathrm{Fe}$ nanoparticles generated by a combined sol-gel/reduction method [60].

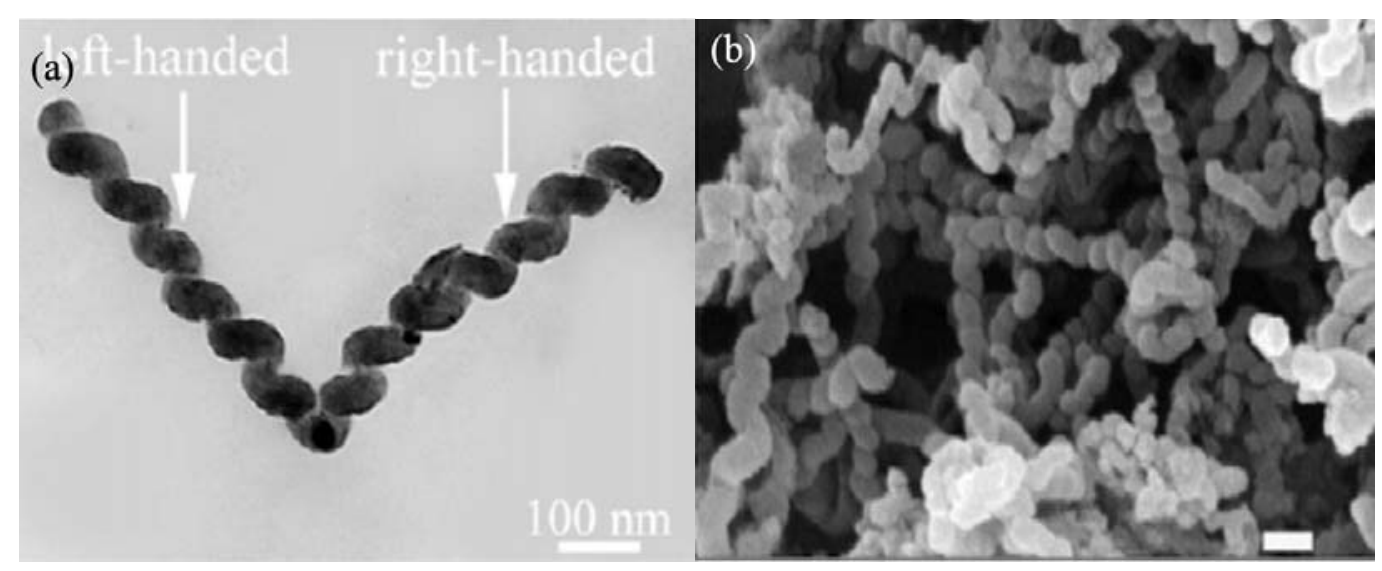


Figure 7. Typical (a) FE-SEM and (b) TEM images of helical carbon nanofibers (HCNTs) synthsized in a quartz reactor over $\mathrm{Fe}$ nanoparticles generated by a combined sol-gel/reduction method [57].

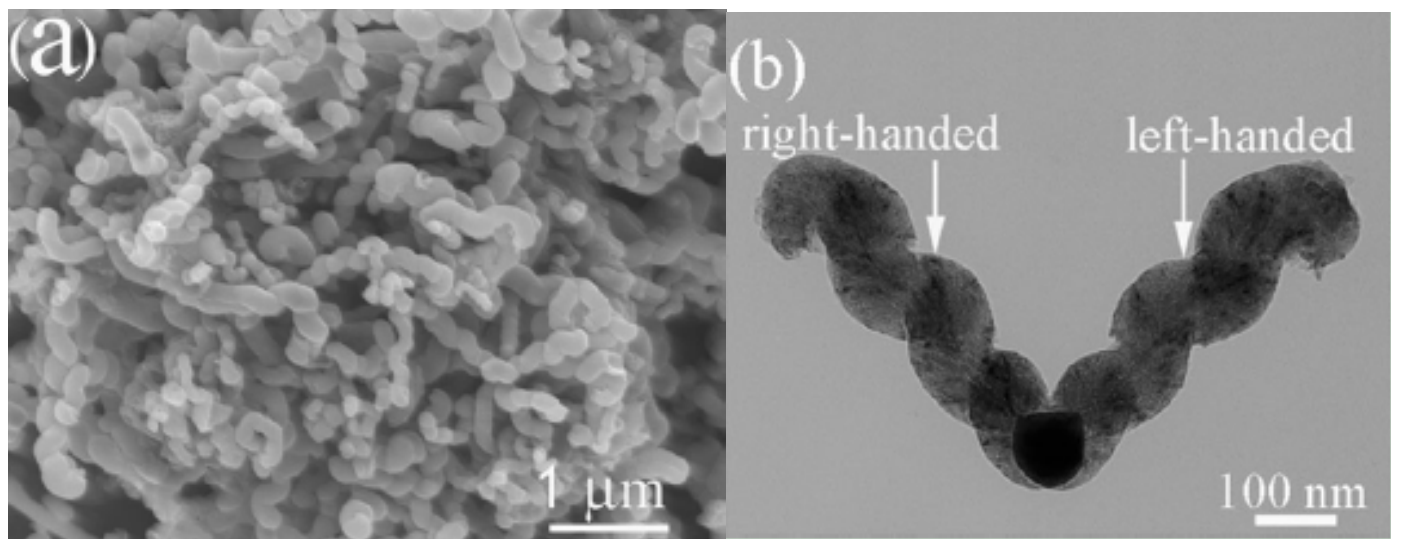

When Ni nanoparticles were used as catalyst, we found that the product collected in acetylene pyrolysis at $415{ }^{\circ} \mathrm{C}$ inside a quartz tube was different from that collected inside a stainless steel tube [61]. The product collected inside a quartz reactor is crystalline plait-like CNCs (3.032 g) (Figure 8a). As shown in Figure 8b, one can see that the plait-like structure exhibits two CNCs of opposite handedness growing alongside each other in a fused manner; the two CNCs are almost identical in diameter, length, pitch, and coil number.

Figure 8. FE-SEM images of plait-like carbon nanocoils (CNCs) collected inside a quartz reactor: (a) Low magnification with white arrows indicating openings of tubes; (b) plait-like CNC with two CNCs fused together in opposite handedness; the left one is left-handed while the right one right-handed [61].
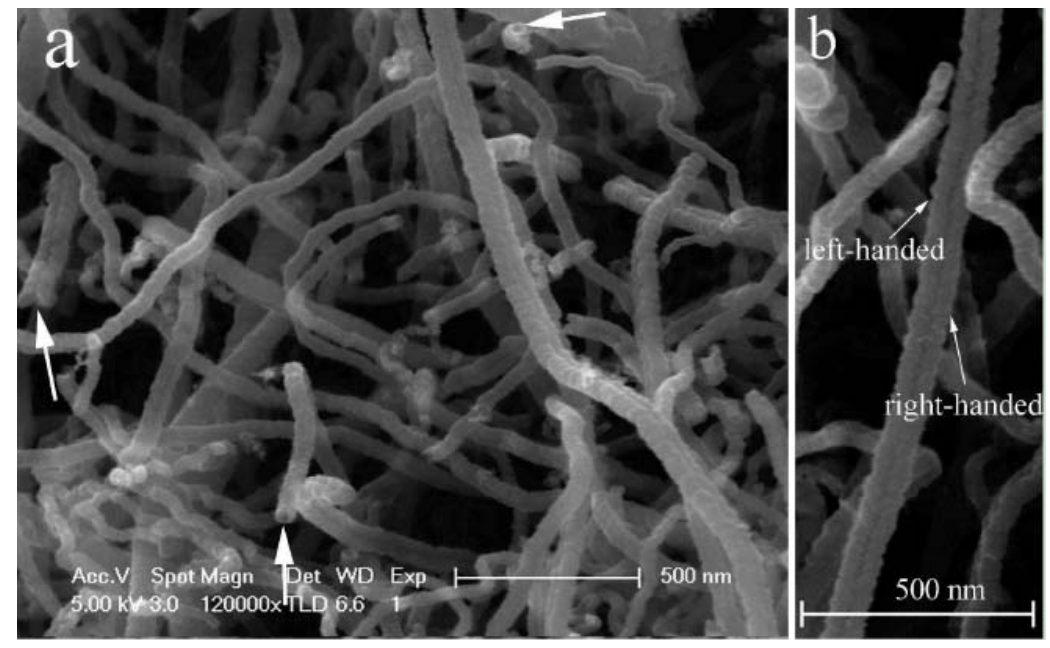

However, if the quartz tube with the Ni catalyst inside was placed in a stainless steel tube, twin carbon nanocoils (T-CNCs) (0.364 g) rather than plait-like CNCs was produced in high selectivity [62]. Figure 9 shows the FE-SEM and TEM images of the as-prepared T-CNCs. The twist and entanglement of CNCs suggest disorder and distortion of material. The T-CNCs have a novel silkworm structure, 
showing tight coils of very short coil pitches. Since the only difference in fabrication procedure was the inclusion of the stainless steel tube, any discrepancy in morphology of the obtained carbon species should be related to reactor modification. We found that both the obtained plait-like CNC and T-CNC materials exhibited good microwave absorbing ability (Table 1). The T-CNC materials T-CNCs are superior to plait-like CNCs in microwave absorption, showing maximum reflection loss (RL) of $-36.09 \mathrm{~dB}$ at $17.29 \mathrm{GHz}$. The results show that reactor design undoubtedly has an impact on the selectivity and kind of carbon species produced in CCVD.

Figure 9. (a) FE-SEM and (b) TEM image of twin carbon nanocoils (T-CNCs) collected inside a quartz tube that was placed inside a stainless steel tube (the arrow indicates the catalyst nanoparticle) [62].

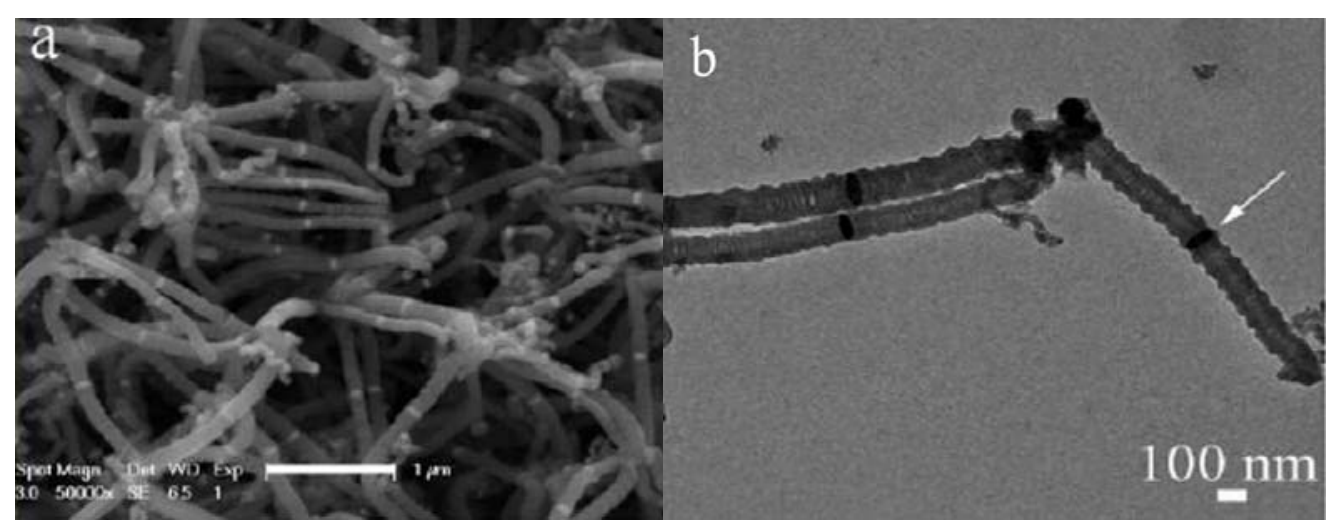

Table 1. Electromagnetic wave absorption properties of the plait-like CNC and T-CNC materials (Figures 8 and 9).

\begin{tabular}{|c|c|c|c|c|}
\hline Reactor setup & Sample & $\begin{array}{l}\text { Optical RL } \\
\text { value (dB) }\end{array}$ & $\begin{array}{c}f_{m}(\mathbf{G H z}) \\
\text { (optical RL) }\end{array}$ & $\begin{array}{l}\text { Frequency range } \\
(\mathrm{RL}<-10 \text { and }-20 \mathrm{~dB})\end{array}$ \\
\hline quartz tube & $\begin{array}{l}\text { plait-like } \\
\text { CNCs }\end{array}$ & -20 & 15.96 & 9.01-18.0 GHz $(-10 \mathrm{~dB})$ \\
\hline $\begin{array}{l}\text { quartz tube placed } \\
\text { inside a stainless } \\
\text { steel tube }\end{array}$ & T-CNCs & -36.09 & 17.29 & $\begin{array}{l}9.00-18.0 \mathrm{GHz}(-10 \mathrm{~dB}) \\
9.00-17.2 \mathrm{GHz}(-20 \mathrm{~dB})\end{array}$ \\
\hline
\end{tabular}

\subsection{Effect of Catalyst Category}

It is obvious that the CCVD technique is suitable for the synthesis of carbon nanomaterials in large quantity. There are two steps involved: (i) synthesis of metallic catalyst such as cobalt, iron, nickel and their alloys; (ii) pyrolysis of hydrocarbon source over catalyst at high temperatures (from 500 to $1000{ }^{\circ} \mathrm{C}$ ). In the past two decades, CNTs were synthesized over Fe [63-68], Co [69-75], Ni [76-81] and their alloys [82-87] through the decomposition of various carbon sources. It is generally accepted that the morphology, size and yield of the obtained carbon nanomaterials are critically determined by the kind of catalyst used [88-91]. Moreover, as shown in Table 2, other inorganic materials such as $\mathrm{Cu}$ [92], $\mathrm{Au}$ [93], $\mathrm{Cu}-\mathrm{Cr}$ [94], Pd-Cr-Pt [95], $\mathrm{Cs}_{2} \mathrm{CO}_{3}$ [96], $\mathrm{Li}_{2} \mathrm{CO}_{3}$ [97] and $\mathrm{K}_{2} \mathrm{CO}_{3}$ [97] were also used as catalysts. Across the iron-, nickel- and cobalt-based catalysts, Klinke et al. [98] observed that the Fe 
catalyst gave the highest selectivity to CNTs in the catalytic decomposition of acetylene at temperatures ranging from 580 to $1000{ }^{\circ} \mathrm{C}$. On the other hand, Lee et al. [99] reported that in the synthesis of CNTs by means of acetylene pyrolysis at $950^{\circ} \mathrm{C}$, the growth rate of CNTs was dependent on the type of catalysts, and catalyst performance was in the order of $\mathrm{Fe}<\mathrm{Co}<\mathrm{Ni}$. The average diameter of the as-synthesized CNTs followed the sequence of $\mathrm{Fe}<\mathrm{Co}<\mathrm{Ni}$, and the crystallinity of CNTs synthesized over Fe catalyst was higher than that over Ni or Co catalyst.

Table 2. Products obtained in the synthesis of carbon nanomaterials by means of acetylene pyrolysis over different catalysts.

\begin{tabular}{|l|l|l|}
\hline Catalyst & Product & Reference \\
\hline $\mathrm{Cu}$ & aligned MWCNTs & {$[92]$} \\
\hline $\mathrm{Au}$ & CNT junctions & {$[93]$} \\
\hline $\mathrm{Cu}-\mathrm{Cr}$ & CNTs & {$[94]$} \\
\hline $\mathrm{Pd}-\mathrm{Cr}-\mathrm{Pt}$ & CNTs & {$[95]$} \\
\hline $\mathrm{Cs}_{2} \mathrm{CO}_{3}$ & CNFs and CNTs & {$[96]$} \\
\hline $\mathrm{Li}_{2} \mathrm{CO}_{3}$ & HCNFs & {$[97]$} \\
\hline $\mathrm{K}_{2} \mathrm{CO}_{3}$ & carbon nanofoam & {$[97]$} \\
\hline
\end{tabular}

Moreover, through the catalytic decomposition of various hydrocarbons, carbon nanomaterials other than CNTs were synthesized over iron-, nickel- and cobalt-based catalysts [100-102]. Over Ni nanoparticles generated through a sol-gel combustion process, Calderon-Moreno et al. [103] synthesized dense carbon nanospheres (CNSs) in the pyrolysis of acetylene at $700{ }^{\circ} \mathrm{C}$. In the pyrolysis of ethylene glycol monoethyl ether $\left(\mathrm{CH}_{3} \mathrm{CH}_{2} \mathrm{OCH}_{2} \mathrm{CH}_{2} \mathrm{OH}\right)$ over Fe catalyst at $650-700{ }^{\circ} \mathrm{C}$, Xi et al. [104] synthesized carbon nanocables and branched-nanobelts. In the co-pyrolysis of $\mathrm{Fe}(\mathrm{CO})_{5}$ and pyridine at $900-1100{ }^{\circ} \mathrm{C}$, Bajpai et al. [45] produced aligned HCNT arrays in large quantity. In the $\mathrm{Ni}$-catalyzed pyrolysis of acetylene containing a small amount of $\mathrm{H}_{2} \mathrm{~S}$, Motojima et al. [105] synthesized carbon microcoils (CMCs) at $700-800{ }^{\circ} \mathrm{C}$. In terms of product yield, the nickel catalysts performed better than the iron ones for the generation of CNCs and CMCs [106-109]. So far, reports on the successful fabrication of CNCs over cobalt catalysts are rare.

In the past decade, we reported the generation of a number of nanomaterials over catalysts of Fe, $\mathrm{Co}$, Ni and their alloys in high yield. We reported that HCNTs (0.413 g) (Figure 7) and HCNFs $(1.582 \mathrm{~g})$ (Figure 6) could be synthesized as main products in the pyrolysis of acetylene over $\mathrm{Fe}$ nanoparticles $(0.035 \mathrm{~g})[57,60]$. The yields (as defined by yield $=\frac{m_{\text {total }}-m_{\text {catalyst }}}{m_{\text {catalyst }}} \times 100 \%$ ) of HCNTs and HCNFs were $1,080 \%$ and 4,420\%, respectively (Table 3). Moreover, due to the encapsulation of Fe nanoparticles, the HCNTs and HCNFs materials showed good magnetic properties (Table 3). Whereas, over Ni nanoparticles (rather than Fe nanoparticles), crystalline plait-like CNCs (Figure 8) or T-CNCs (Figure 9) were produced [61,62]. It is worth noting that the maximum yield of plait-like CNCs and T-CNCs was ca. $18,760 \%$ and $6,014 \%$, respectively, much higher than that of HCNTs or HCNFs synthesized over Fe nanoparticles. It is clear that the growth rate of carbon nanomaterials was strongly dependent on the type of the catalysts. 
Table 3. Yield and magnetic property of helical carbon nanofibers (HCNFs) and helical carbon nanotubes (HCNTs).

\begin{tabular}{|l|l|l|l|l|}
\hline Reactor & Product yield & Product & $\begin{array}{l}\text { Saturation } \\
\text { magnetization }\left(\boldsymbol{M}_{\mathbf{S}}\right)\end{array}$ & Coercivity $\left(\boldsymbol{H}_{\mathbf{c}}\right)$ \\
\hline stainless steel tube & $4,420 \%$ & HCNFs & $4.99 \mathrm{emu} / \mathrm{g}$ & $91.61 \mathrm{Oe}$ \\
\hline quartz tube & $1,080 \%$ & HCNTs & $12.11 \mathrm{emu} / \mathrm{g}$ & $240.07 \mathrm{Oe}$ \\
\hline
\end{tabular}

\subsection{Effect of Catalyst Preparation Procedure}

It is known that the dispersion level of a material has influence on its catalytic property. Unlike the fine and well dispersed particles, the large particles and aggregates were inactive for the growth of carbon nanomaterials [110]. It was reported that large surface area and well dispersion of a catalyst (i.e., small in particle size) has a positive effect on the yield and size distribution of as-synthesized carbon nanomaterials [111]. In other words, in order to produce carbon nanomaterials in large quantity, one must prepare catalysts in the form of nanoparticles. For the generation of catalysts or catalyst precursors, techniques such as sol-gel approaches [60-62], incipient wetness impregnation [112-114], co-reduction of precursors [115-116], ion-exchange-precipitation [117-120], lithography [121] and ion-adsorption-precipitation [122] are often used. Since the size of catalyst nanoparticles is dependent on the preparation method, the method for catalyst preparation has an effect on the performance of the as-prepared catalyst [109,123]. In a study of Avdeeva et al. [124], various alkali solutions $(\mathrm{NaOH}$, $\mathrm{NH}_{4} \mathrm{OH}$ and $\mathrm{Na}_{2} \mathrm{CO}_{3}$ ) were used to deposit Co nitrate for the formation of different Co precursors. For the generation of filamentous carbon, the best performance was found over the catalyst prepared using $\mathrm{NaOH}$ as precipitant [124]. In methane decomposition over $\mathrm{Ni}-\mathrm{Al}_{2} \mathrm{O}_{3}$ catalysts, it was found that the catalyst prepared using $\mathrm{NaOH}$ as precipitant performed the best $[125,126]$.

Lately, we reported a simple, environmentally friendly and inexpensive route for the generation of HCNTs in large quantity (2.651 g). As shown in Figure 7, over Fe nanoparticles generated by a combined sol-gel/hydrogen reduction method, HCNTs (consist of two HCNTs and a catalyst nanoparticle) were synthesized as major product (selectivity $=85 \%$; yield $=1,080 \%$ ) in the pyrolysis of acetylene at $450{ }^{\circ} \mathrm{C}$ [57]. When $\mathrm{Fe}$ nanoparticles were fabricated using a combined coprecipitation/hydrogen reduction method instead, HCNTs were synthesized in much higher selectivity (93\%) and yield (7,474\%) (Figure 10a) [34], higher than any reported in the literature. The HCNTs are composed of two or three coiled nanotubes that are connected to a catalyst nanoparticle (Figure 10b). The diameters of the tubes are in the range of 50 to $100 \mathrm{~nm}$, smaller than that of HCNTs shown in Figure 7 [57]. All the results confirm that the method for catalyst preparation has an effect on the shape and yield of final products. 
Figure 10. (a) FE-SEM and (b) TEM images of helical carbon nanotubes (HCNTs) synthesized over $\mathrm{Fe}$ nanoparticles generated by means of combined coprecipitation/hydrogen reduction method. Note: the arrows in Figure 10a indicate the opening of HCNTs and the arrow in Figure 10b indicates the catalyst nanoparticle [34].

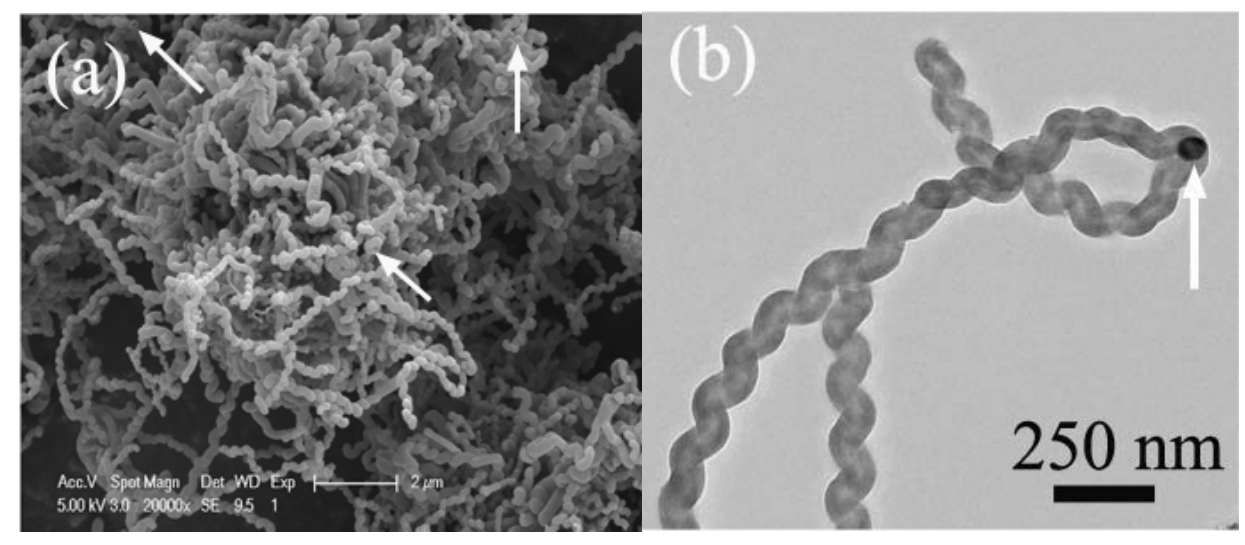

\subsection{Effect of Support Materials}

It was found that supporting a metal or a mixture of metals on oxides, zeolites, clays, or conductive substrates would result in enhancement of catalytic activity in the synthesis of carbon nanomaterials [127-130]. It is apparent that the interaction between catalyst and support has a positive effect on the growth of carbon entities. Materials such as $\mathrm{SiO}_{2}$ [131,132], $\mathrm{MgO}[133,134], \mathrm{Al}_{2} \mathrm{O}_{3}$ [135,136], CNTs $[137,138]$, stainless steel [139,140], zeolite [141,142], as well as some other materials [143,144] were used as supports for the synthesis of carbon nanomaterials (Table 4). The interactions between a metal catalyst and its support can be either physical or chemical. As suggested by Vander Wal et al. [145], physical interaction between metal and support could have an effect on the size distribution of catalyst particles. In chemical interactions, charge transfer can take place via different pathways, e.g. through oxidation/reduction processes or acid/base (donor/acceptor) reactions. When the support is a metal oxide, oxidation/reduction reactions occur through the transfer of an oxygen atom from support to metal and vice versa. Acid/base interactions are linked to the Lewis acid and base characters of the materials. In the cases of metal oxides, surface anions act as Lewis base sites (electron pair donor) and cations as Lewis acid sites (electron pair acceptor). The interaction between the catalyst and its support can affect the electronic nature of the catalyst and hence have an effect on the dispersion of the metal on its support. For example, quartz, conductive glass, porous alumina and nickel plates were used by Ortega-Cervantes et al. [146] to support Fe and Co catalysts for the synthesis of CNTs using ethanol as carbon source. Successive growth of nanotubes was observed when conducting glass, nickel plates or porous alumina was used as support. Over the catalyst supported on nickel plate and porous alumina substrates, SWNTs were generated whereas over that supported on conducting glass, MWNTs were synthesized.

In a paper on the synthesis of double-walled CNTs over metal catalysts supported on mesoporous silica, Zhu et al. [147] suggested that the support was acting as template for the initial growth of CNTs. They found that when the mass fraction of Fe and Co (catalyst/support) was between $1.5 \%$ and $3 \%$, double-walled CNTs were synthesized in high selectivity, and at mass fraction of $6 \%$ most of the products were MWNTs. Lately, we reported the controllable synthesis of CNFs, bamboo-like CNTs 
and chains of carbon nanospheres (CNSs) in large quantities over $\mathrm{Fe} / \mathrm{SnO}_{2}$ nanoparticles generated by means of a combined sol-gel and hydrogen reduction method in the pyrolysis of acetylene at $500{ }^{\circ} \mathrm{C}$, $600{ }^{\circ} \mathrm{C}$ and $700{ }^{\circ} \mathrm{C}$, respectively [148]. The results demonstrated that synergistic effect of catalyst and support must be considered in CCVD processes. Nonetheless, the use of a support in the synthesis of carbon nanomaterials has its disadvantages. First, there could be the formation of undesirable intermediates. Second, further treatments are required if one has to remove the support material from the products [149]. It is likely that the separation and purification treatment would cause cost increase and damage of product. Therefore, it is good to avoid using a support or to select a support that can be easily removed without causing much damage to the product [145].

Table 4. Examples of supported catalysts used in CCVD synthesis.

\begin{tabular}{|l|l|l|l|}
\hline Catalyst & Support material & Product & Reference \\
\hline $\mathrm{Ni}$ & $\mathrm{SiO}_{2}$ & SWNTs & {$[132]$} \\
\hline $\mathrm{Fe}-\mathrm{Co}$ & $\mathrm{MgO}$ & SWNTs & {$[134]$} \\
\hline $\mathrm{Fe}$ & $\mathrm{Al}_{2} \mathrm{O}_{3}$ & MWNTs & {$[136]$} \\
\hline $\mathrm{Ni}$ & $\mathrm{CNTs}$ & CMCs/CNCs & {$[138]$} \\
\hline $\mathrm{Fe}$ & stainless steel & aligned MWNTs & {$[141]$} \\
\hline $\mathrm{Co}-\mathrm{Fe}$ & zeolite & double-walled CNTs & {$[142]$} \\
\hline $\mathrm{Ni}$ and $\mathrm{Co}$ & $\mathrm{CaCO}$ & MWNTs & {$[143]$} \\
\hline $\mathrm{Fe}$ & $\mathrm{ITO}_{3}$ & CNCs & {$[144]$} \\
\hline
\end{tabular}

\subsection{Effect of Catalyst Promoters}

To enhance catalytic activity and to increase selectivity to carbon nanomaterials, metals such as $\mathrm{Cu}$ [150], Cr [151], Mo [152], In and Sn [153] were added to catalysts as promoters. For example, $\mathrm{Cu}$ was added to modify the catalytic properties of $\mathrm{Ni}$ and $\mathrm{Co}$ [154-156]. In the cases of alloys, Cu was added as an impurity to change the crystalline state of metal ensembles [154,155] or to improve the wetting characteristics of graphite on catalyst [156]. Furthermore, it is known that Fe, Co and Ni nanoparticles provide centers for carbon nucleation and act as active sites for the decomposition of carbon species. Nonetheless, due to magnetic nature and high surface energy, nanoparticles have a high tendency to agglomerate at high temperature (generally above $700{ }^{\circ} \mathrm{C}$ ). In order to retain high dispersion of $\mathrm{Ni}$ during $\mathrm{C}_{2} \mathrm{H}_{2}$ pyrolysis at $700{ }^{\circ} \mathrm{C}$ for the generation of aligned CNTs, Chen et al. [157] added Cr into the $\mathrm{Ni}$ catalyst for the formation of Ni-Cr alloy films. They found that the dispersion of $\mathrm{Ni}$ on the film surfaces strongly depended on the thickness ratio of $\mathrm{Ni}$ and $\mathrm{Cr}$ layers. One could optimize the density of well aligned CNTs by adjusting the thickness ratio.

As active catalysts for hydrodesulfurization, bimetallic Co-Mo materials have been studied for decades $[158,159]$. Recently, the catalysts were used for the selective synthesis of SWNTs [160-163]. Over Co-Mo catalysts prepared from metal acetate solutions and using alcohol as carbon source, Murakami and coworkers [164-167] generated SWNTs that were randomly or vertically aligned on quartz glass. It was reported that catalytic performance follow the order: Co(acetate)-Mo(acetate) > $\mathrm{Co}$ (nitrate) $-\mathrm{Mo}$ (acetate) $>>\mathrm{Co}$ (acetate) $>>\mathrm{Mo}$ (acetate). For the synthesis of SWNTs over Co-Mo using $\mathrm{CO}$ as carbon source, Borgna and coworkers [168-171] related the ability to produce SWNTs to 
the structure and composition of Co-Mo catalysts. They suggested that at optimum Co/Mo ratio, the Co species were stabilized by Co molybdate upperlayers or underlayers during reduction, and the role of Mo carbide was to provide the catalytically active metallic Co particles with active carbon. It was reported by Kitiyanan et al. [172] that Mo alone was not active for the synthesis of SWNTs but the copresence of Mo and Co would greatly enhance the formation of SWNTs. The results strongly suggest that the synergism of Co and Mo determines the generation of SWNTs in CCVD processes.

Furthermore, it was observed that the selectivity to HCNTs and CNCs was greatly enhanced when In and Sn were introduced to Fe catalysts. For example, Okazaki et al. [173] synthesized CNCs in high selectivity over Fe-In-Sn-O fine particles. By optimizing the composition ratios of Fe, In (between 10 and $33 \%$ of $\mathrm{Fe}$ ) and $\mathrm{Sn}$ (less than $3.3 \%$ of $\mathrm{Fe}$ ), CNCs could be grown in high selectivity. Moreover, using Fe and indium tin oxide (ITO) as catalysts, Pan et al. [174] selectively produced carbon tubule nanocoils in CCVD of acetylene. It was reported that the selectivity to CNCs was determined by the molar ratio of Sn and In, and the growth of CNTs was related to Fe whereas the helical growth to ITO.

Recently, we reported the effect of introducing $\mathrm{Cu}$ to $\mathrm{Fe}_{2} \mathrm{O}_{3}$ precursor on the pyrolysis of acetylene [175]. Over $\mathrm{Fe}-\mathrm{Cu}$ nanoparticles derived from sol-gel synthesis followed by hydrogen reduction at $400{ }^{\circ} \mathrm{C}, \mathrm{HCNT}$ and $\mathrm{CNBs}$ were produced in large quantities at $450{ }^{\circ} \mathrm{C}$. As indicated in Figure 11, the black product was labeled $\mathrm{X}_{400}$ while the brown one $\mathrm{Y}_{400}$. The FE-SEM images of $\mathrm{X}_{400}$ show that the selectivity to HCNTs (ca. 85\%) is high (Figure 12). Unlike the case of generating double-HCNTs over $\mathrm{Fe}$ at $450{ }^{\circ} \mathrm{C}$ (Figure 7) [62], plait-like HCNTs are produced. One can see openings of CNTs as indicated by arrows in Figure 12.

Figure 11. Photo of $\mathrm{X}_{400}$ and $\mathrm{Y}_{400}$ deposited on a ceramic plate [175].

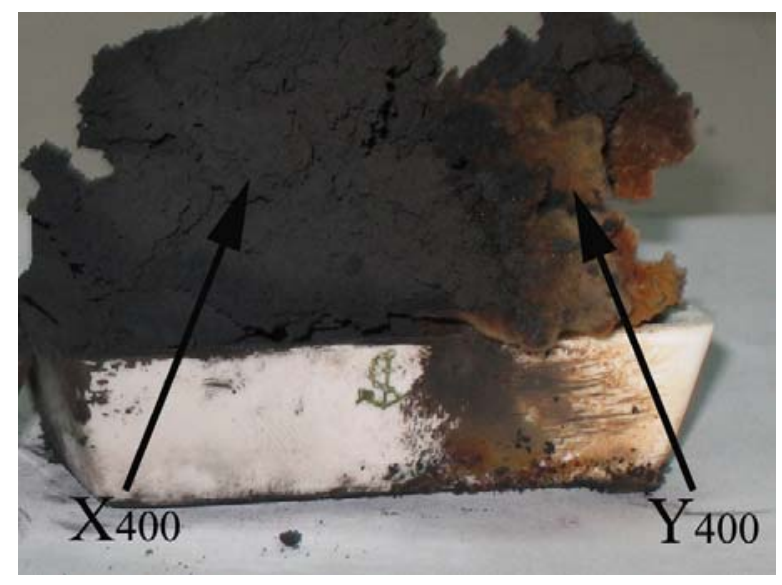

The FE-SEM images of $\mathrm{Y}_{400}$ are shown in Figure 13. The majority of the product is CNBs (ca. 90\%). The amount of $\mathrm{Y}_{400}$ collected was $3.468 \mathrm{~g}$, slightly higher than one-third of the total mass $(9.504 \mathrm{~g}$ of $\mathrm{X}_{400}$ and $\mathrm{Y}_{400}$ ). In other words, the yield of CNBs was ca. 9,867\%. The results of a series of comparison experiments designed to investigate the influence of synthesis conditions confirmed that the presence of $\mathrm{Cu}$ in the catalyst is crucial for CNBs fabrication. 
Figure 12. (a-b) FE-SEM images of $\mathrm{X}_{400}$ at different magnifications (the arrows indicate the opening of HCNTs) [175].

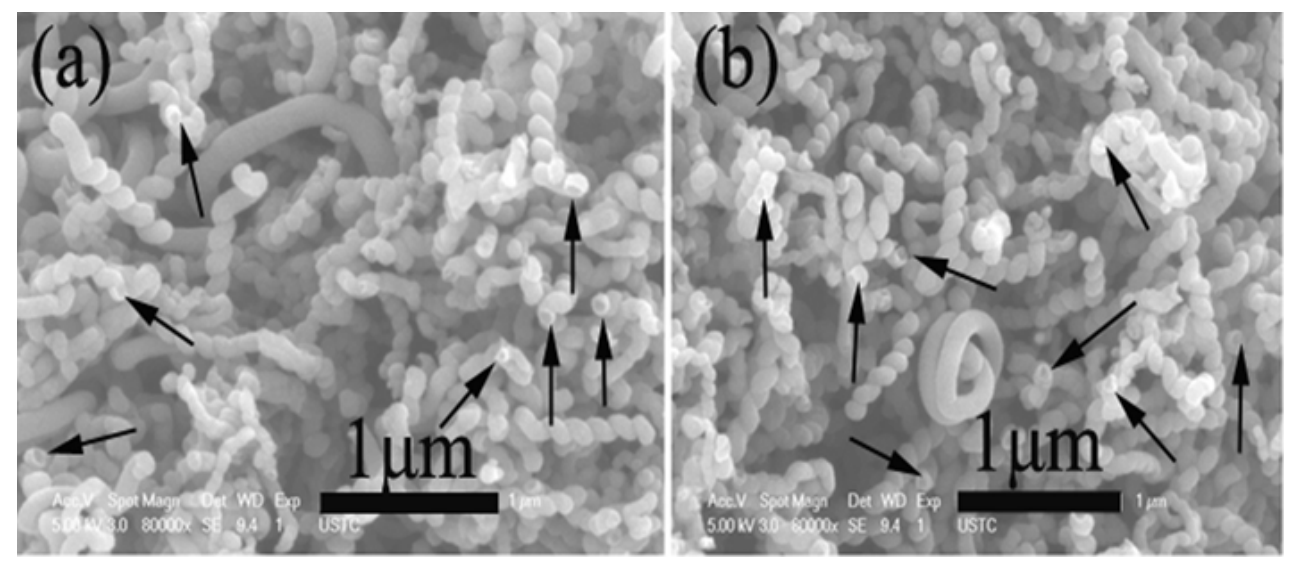

Figure 13. (a-b) FE-SEM images of $\mathrm{Y}_{400}$ at different magnifications [175].
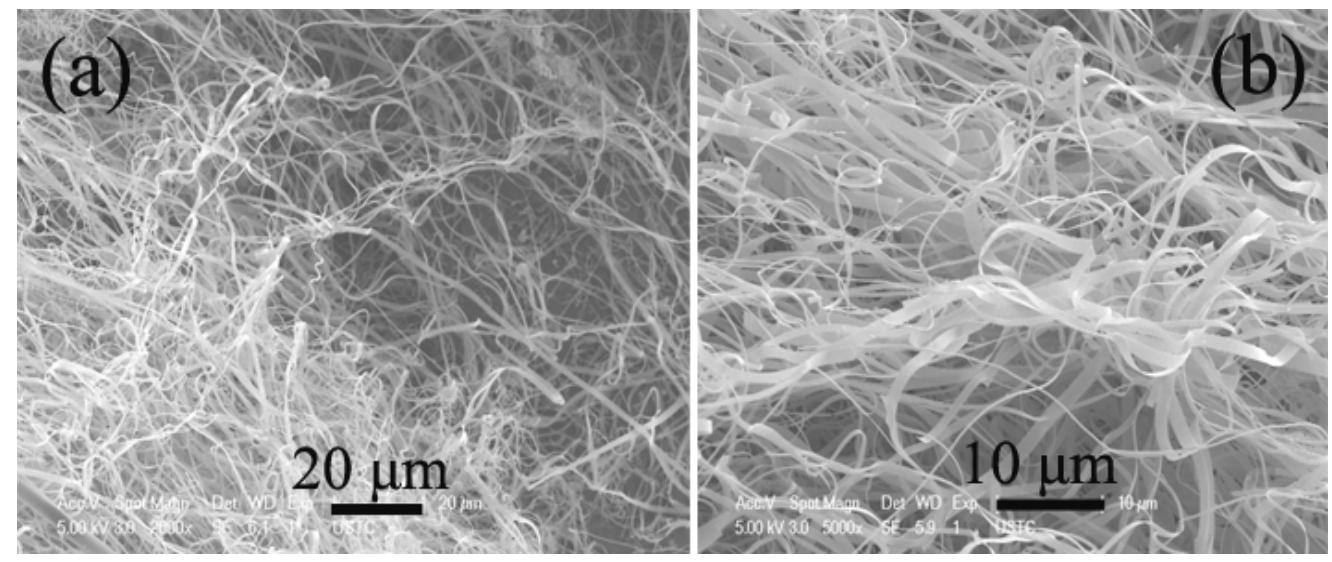

\subsection{Effect of Reduction Temperature of Catalyst Precursors and Presence of Hydrogen in Carbon Source}

As mentioned above, the catalyst precursors were synthesized and reduced in hydrogen at different temperatures to generate the corresponding metal catalysts (Fe, Co or Ni) $[57,62,175]$. It is noted that the temperature adopted for the reduction of precursors has an effect on the final products [176-179]. Reduction is an important process, which determines the energetic state and the size of the metal particles. Piao et al. [180] studied the effect of reduction temperature of catalyst precursor $\left(580,700\right.$ and $800{ }^{\circ} \mathrm{C}$ ) on the synthesis of CNTs over $\mathrm{Ni} / \mathrm{Al}_{2} \mathrm{O}_{3}$ at $575{ }^{\circ} \mathrm{C}$ using a feed of $\mathrm{CH}_{4}: \mathrm{N}_{2}=1: 2$. They found that the amount, morphology and the growth rate of CNTs depended on the reduction temperature. In the CVD of methane over $\mathrm{Co}-\mathrm{Mo} / \mathrm{Al}_{2} \mathrm{O}_{3}$ catalysts in a stainless steel fixed-bed reactor at $700{ }^{\circ} \mathrm{C}$, Chai et al. [181] observed that the reduction temperature had great impact on CNT selectivity and diameter uniformity. Their results showed that an increase in reduction temperature could produce metal particles that are slightly larger in average diameter and wider in diameter distribution. Also, with an increase of reduction temperature of catalyst precursor, better graphitization of CNTs was observed. 
The effect of $\mathrm{H}_{2}$ presence during pyrolysis process on as-synthesized carbon nanomaterials can be significant. Signore et al. [178] found that CNTs could be synthesized at $700{ }^{\circ} \mathrm{C}$ over Fe catalyst in $\mathrm{C}_{2} \mathrm{H}_{2} / \mathrm{H}_{2}$ flows (ranging from $5 / 95$ to $30 / 70$ ), and when $\mathrm{C}_{2} \mathrm{H}_{2} / \mathrm{H}_{2}$ flow rate was greater than $20 \%$ vertically aligned CNTs were fabricated in $7 \mathrm{~min}$ of deposition time. Also, in the synthesis of carbon coils in $\mathrm{H}_{2} / \mathrm{C}_{2} \mathrm{H}_{2}$ flows over $\mathrm{Ni}$ catalysts, Chen et al. [182] observed that at low $\mathrm{H}_{2}$ flow rate (i.e., low $\mathrm{H}_{2} / \mathrm{C}_{2} \mathrm{H}_{2}$ flow ratio), there was the formation of irregular carbon coils (different in coil diameters and irregular in coil diameters) as well as the formation of single coils, straight fibers and irregular fibers. At high $\mathrm{H}_{2}$ flow rate (i.e., high $\mathrm{H}_{2} / \mathrm{C}_{2} \mathrm{H}_{2}$ flow ratio), there was the preferable formation of short coils, and the yield of regular coils was poor. It is apparent that the amount of hydrogen in acetylene affects the kind of hydrocarbon intermediates being formed, and thus affects the growth characteristic of carbon coils. Moreover, under the conditions of: catalyst $=\mathrm{Ni}$, reaction temperature $=770{ }^{\circ} \mathrm{C}$, reaction time $=60 \mathrm{~min}$, and gas flow: $\mathrm{C}_{2} \mathrm{H}_{2}=83 \mathrm{sccm}, \mathrm{N}_{2}=400 \mathrm{sccm}, \mathrm{H}_{2} \mathrm{~S} / \mathrm{H}_{2}=70 \mathrm{sccm}$, Chen et al. [183] observed the formation of CMCs. The authors reported that when $\mathrm{H}_{2}$ flow rate was below $75 \mathrm{sccm}$, only carbon powder was produced. Between $\mathrm{H}_{2}$ flow rate of 100 and $250 \mathrm{sccm}$, there was steep increase of circular CMCs. Maximum selectivity (85\%) to CMCs was attained at $250 \mathrm{sccm}$, and selectivity to $\mathrm{CMCs}$ declined to $60 \%$ at $\mathrm{H}_{2}$ flow rate of $430 \mathrm{sccm}$.

As mentioned above, over the $\mathrm{Fe}-\mathrm{Cu}$ nanoparticles $(0.037 \mathrm{~g})$ derived from sol-gel synthesis of $\mathrm{Fe}_{2} \mathrm{O}_{3} / \mathrm{CuO}$ followed by hydrogen reduction at $400{ }^{\circ} \mathrm{C}$, HCNTs and CNBs $(9.504 \mathrm{~g})$ were synthesized simultaneously in large quantities in acetylene decomposition at $450{ }^{\circ} \mathrm{C}$ [175]. The yield of carbon species is extremely high, up to $c a .27,307 \%$ (Figure 11). The amount of $\mathrm{Y}_{400}$ (CNBs) collected was $3.468 \mathrm{~g}$ (corresponding to a yield of $c a .9,867 \%$ ) slightly higher than one-third of the total mass. When reduction temperature of $\mathrm{Fe}_{2} \mathrm{O}_{3} / \mathrm{CuO}$ was $450{ }^{\circ} \mathrm{C}$ (other experimental conditions were kept equal), the amount of black and brown products (denoted as $\mathrm{X}_{450}$ and $\mathrm{Y}_{450}$ as indicated in Figure 14) collected was $3.860 \mathrm{~g}$ (corresponding to a yield of around 10,994\%), much lower than that of $\mathrm{X}_{400}$ and $\mathrm{Y}_{400}$. Compared to $\mathrm{Y}_{400}, \mathrm{Y}_{450}$ was deeper in color and higher in amount. After separation, $1.831 \mathrm{~g}$ of $\mathrm{Y}_{450}$ was collected (almost half of the total mass), giving a CNB yield of ca. 5,163\%, much lower than that of $\mathrm{Y}_{400}$.

Figure 14. Photo of $\mathrm{X}_{450}$ and $\mathrm{Y}_{450}[175]$.

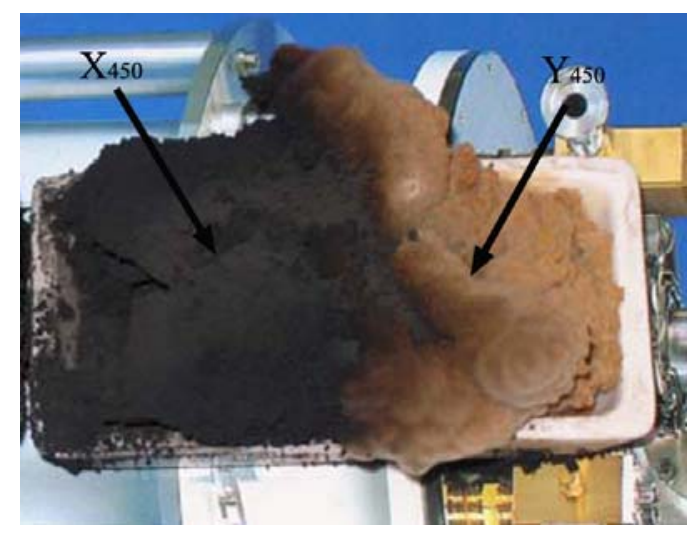

FE-SEM and TEM observations of $\mathrm{X}_{450}$ indicated that HCNTs and worm-like CNTs were produced in large amounts. The selectivity to HCNTs in the case of $\mathrm{X}_{450}$ is poorer than that in the case of $\mathrm{X}_{400}$. 
The FE-SEM and TEM investigations of $\mathrm{Y}_{450}$ showed that the selectivity to CNBs was up to ca. $90 \%$. The CNBs are wider than those observed in $\mathrm{Y}_{400}$. It is hence deduced that the reduction temperature of catalyst precursor has profound effects on the yield and morphology of products. In order to confirm such a view, the $\mathrm{Fe}_{2} \mathrm{O}_{3} / \mathrm{CuO}$ powder was reduced at $500{ }^{\circ} \mathrm{C}$. After the completion of the pyrolysis process, $2.342 \mathrm{~g}$ of black and brown products (denoted as $\mathrm{X}_{500}$ and $\mathrm{Y}_{500}$ ) was collected (Figure 15), giving a yield of $c a .6,631 \%$. In contrast to $\mathrm{X}_{400}$ (Figure 11) and $\mathrm{X}_{450}$ (Figure 14), there were CNTs of low helicity (L-HCNTs) in $\mathrm{X}_{500}$ and the content of CNBs in $\mathrm{Y}_{500}$ was at least up to $c a .90 \%$. Compared to that of $\mathrm{Y}_{400}$ and $\mathrm{Y}_{450}$, the content of $\mathrm{Y}_{500}(2.342 \mathrm{~g}$ ) was high. After separation, $1.263 \mathrm{~g}$ (exceeding half of the total mass) of $\mathrm{Y}_{500}$ was obtained, and the yield of CNBs was up to 3,530\%. It is clear that a rise of reduction temperature from 400 to $500{ }^{\circ} \mathrm{C}$ favors the generation of CNBs but lowers the total yield of carbon nanomaterials. Since the decomposition of acetylene was conducted at equal temperature $\left(450{ }^{\circ} \mathrm{C}\right)$ in the three cases, any discrepancy in yield and morphology of carbon species should be related to the reduction temperature of catalyst precursor.

Figure 15. Photo of $X_{500}$ and $Y_{500}[175]$.

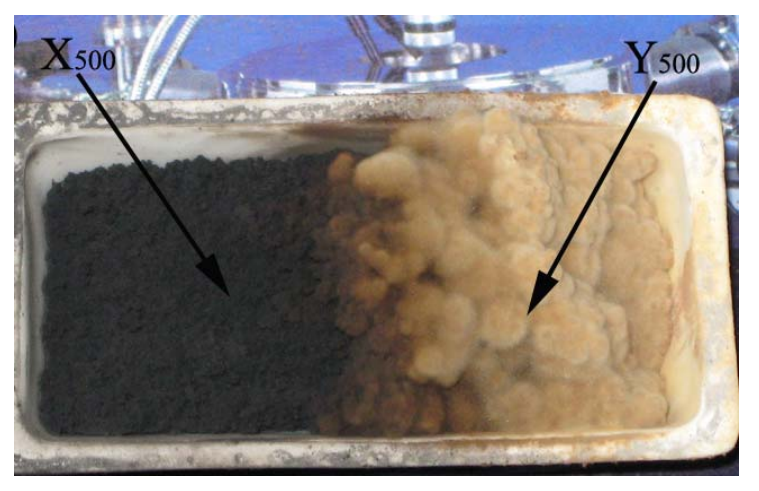

It was also observed that the temperature for $\mathrm{NiO}$ reduction has a profound influence on the morphology and yield of as-synthesized plait-like CNCs [60]. If $\mathrm{NiO}$ was reduced in $\mathrm{H}_{2}$ at $375{ }^{\circ} \mathrm{C}$ for $1 \mathrm{~h}, 3.705 \mathrm{~g}$ (corresponding to a yield of $c a .18,760 \%$ ) of crystalline plait-like CNCs was synthesized in the pyrolysis of acetylene at $425{ }^{\circ} \mathrm{C}$. The plait-like CNCs showed good ability for microwave absorption. If the temperature for $\mathrm{NiO}$ reduction was $400{ }^{\circ} \mathrm{C}$ (rather than $375^{\circ} \mathrm{C}$ ) and with the other experimental conditions kept equal, the decomposition of acetylene became very fast (completion in $12 \mathrm{~min}$ ), and the observed carbon yield was ca. $4.198 \mathrm{~g}$ (corresponding to a carbon yield of $c a$. 21,270\%). The TEM and FE-SEM investigations showed that there was a dense population of single helicals among the product and the amount of plait-like CNCs was low. In other words, with a rise of temperature (from 375 to $400{ }^{\circ} \mathrm{C}$ ) for the reduction of $\mathrm{NiO}$ precursor, the selectivity to single $\mathrm{CNCs}$ became high and that to plait-like CNCs low.

We also investigated the effect of hydrogen flow rate during the pyrolysis process on morphology, yield, and magnetic property of carbon products. As pointed out before [34], over Fe nanoparticles derived from coprecipitation/hydrogen reduction method, HCNTs (2.651 g) (as shown in Figure 12) could be synthesized in large-scale in the pyrolysis of acetylene at $450{ }^{\circ} \mathrm{C}$ and the yield of HCNTs is ca. 7,474\%. TEM and FE-SEM investigations indicated that the as-synthesized HCNTs showed high helicity (H-HCNTs) in comparison to those of HCNTs reported by Bajpai [44], Hou et al. [46], and 
Tang et al. [57]. Moreover, the HCNT material showed good microwave absorbing ability [184]. If hydrogen was introduced to the reaction tube at low rate $\left(\mathrm{C}_{2} \mathrm{H}_{2} / \mathrm{H}_{2}=5: 1\right)$ and the other experimental conditions were kept unchanged, $0.526 \mathrm{~g}$ of L-HCNTs (low helicity of HCNTs) was collected. The corresponding yield was ca. 1,403\%, much lower than that of H-HCNTs (Figure 12). A comparison between the H-HCNT and L-HCNT material showed that the latter exhibited better microwave absorption properties than the former [184]. In general, by controlled introduction of hydrogen into the reaction tube, H-HCNTs, L-HCNTs and worm-like CNTs could be fabricated in the catalytic decomposition of acetylene over Fe nanoparticles generated by a combined coprecipitation/hydrogen reduction method. When the $\mathrm{H}_{2}$ flow rate was enhanced $\left(\mathrm{C}_{2} \mathrm{H}_{2} / \mathrm{H}_{2}=5: 3\right), 0.312 \mathrm{~g}$ of worm-like CNTs (selectivity $=88 \%$ ) was obtained, and the corresponding yield of carbon species is $c a .891 \%$, much lower than that of H-HCNTs and L-HCNTs. Compared to that of H-HCNTs and L-HCNTs, the helicity of worm-like CNTs can be considered as zero. Through FE-SEM and TEM observations of the obtained samples, we found that the size of catalyst nanoparticles (ca. $200 \mathrm{~nm}$ ) of worm-like CNTs is much larger than that of H-HCNTs and L-HCNTs (ca. 40 and $60 \mathrm{~nm}$, respectively). It is clear that the introduction of hydrogen and rate of hydrogen introduction have an effect on CNT helicity as well as on the size of entrapped catalyst nanoparticles. In terms of yield, morphology and helicity of CNTs products, there are distinct variations among the obtained H-HCNTs, L-HCNTs and worm-like CNTs. Moreover, as shown in Table 5, the as-synthesized worm-like CNT material is superior to the H-HCNT and L-HCNT material in microwave absorption.

Table 5. Electromagnetic wave absorption properties of as-synthesized H-HCNT, L-HCNT and worm-like CNT samples.

\begin{tabular}{|l|l|l|l|l|}
\hline Sample & $\begin{array}{l}\text { Optical RL } \\
\text { value }(\mathbf{d B})\end{array}$ & $\begin{array}{l}d_{m}(\mathbf{m m}) \\
(\mathbf{R L}<-\mathbf{2 0} \mathbf{~ d B})\end{array}$ & $\begin{array}{l}f_{m}(\mathbf{G H z}) \\
(\mathbf{o p t i c a l ~ R L )})\end{array}$ & $\begin{array}{l}\text { Frequency range } \\
(\mathbf{G H z})(\mathbf{R L}<-\mathbf{2 0} \mathbf{d B})\end{array}$ \\
\hline H-HCNTs & -8.25 & - & 11.8 & - \\
\hline L-HCNTs & -25.78 & $2.0-3.0$ & 7.18 & $7.18-10.68$ \\
\hline worm-like CNTs & -26.39 & $2.0-3.0$ & 7.71 & $7.5-10.7$ \\
\hline
\end{tabular}

\subsection{Effect of Reaction Temperature}

In previous studies, it was found that the yield and structure of as-synthesized carbon materials were dependent on the reaction temperature [185-189]. For example: Li et al. [190] reported the synthesis of MWNTs over Ni/Al catalyst in methane decomposition at $450-650{ }^{\circ} \mathrm{C}$. They found that the yield of MWNTs increased with rise of pyrolysis temperature and this effect became more apparent at high temperatures. They reported that CNTs poor in structure and low in crystallinity were formed at low temperatures due to the low catalytic activity of nickel and poor reactivity of carbon atoms. The effect of reaction temperature was also reported by Singh et al. [191]. They found that at $550{ }^{\circ} \mathrm{C}$, the yield of MWNTs over an iron catalyst was low. When the reaction temperature was raised to 590,740 or $850{ }^{\circ} \mathrm{C}$, film with aligned CNTs was formed. According to the results of TEM investigation, the diameters of the nanotubes increased with rise of reaction temperature. At $940{ }^{\circ} \mathrm{C}$, the quantity of CNTs decreased; alignment was lost and a large number of encapsulated particles were formed. For the generation of HCNFs, Tang et al. [60] achieved high selectivity to coiled nanofibers in 
acetylene pyrolysis over Fe nanoparticles at $450{ }^{\circ} \mathrm{C}$ in a stainless steel tube. At $700{ }^{\circ} \mathrm{C}$, fibers with straight and/or irregular shapes became major product. The amount of carbon products generated at $700{ }^{\circ} \mathrm{C}$ was $15.753 \mathrm{~g}$, much higher than that of $\mathrm{HCNFs}$ generated at $450{ }^{\circ} \mathrm{C}$. The results again indicated that the yield and morphology of CNFs was dependent on reaction temperature.

In CMC synthesis, Chen et al. [182] found that coil diameters and morphology of carbon coils and diameter of carbon fibers that built up the carbon coils were significantly affected by reaction temperature. The regular carbon coils with an average coil diameter of about $5 \mu \mathrm{m}$ and an average fiber diameter of about $0.7 \mu \mathrm{m}$ were obtained at temperatures between $760-790{ }^{\circ} \mathrm{C}$. Below $760{ }^{\circ} \mathrm{C}$, the formation of CMCs was insignificant. At $700{ }^{\circ} \mathrm{C}$, only noodle-like twin fibers were formed whereas at $740{ }^{\circ} \mathrm{C}$, a smaller number of carbon coils was formed, showing coil diameters and coil pitches larger than those of the CMCs obtained in the $760-790{ }^{\circ} \mathrm{C}$ range. At higher temperature such as $870{ }^{\circ} \mathrm{C}$, a small amount of irregular carbon coils with larger coil diameters were produced. Similar phenomena were observed in the synthesis of T-CNCs [62] and plait-like CNCs [61]. When the reaction temperature was changed from 415 to $425^{\circ} \mathrm{C}$ (other conditions unchanged), T-CNCs $(2.41 \mathrm{~g})$ larger in length and diameter (ca. $160 \mathrm{~nm}$ ) were obtained over Ni nanoparticles. We observed that the coils were composed of small nanocoils of very small diameter. As compared to that of $0.364 \mathrm{~g}$ at $415{ }^{\circ} \mathrm{C}$, there is a significant increase in T-CNC yield at $425^{\circ} \mathrm{C}$. On the other hand, $3.302 \mathrm{~g}$ of plait-like CNCs were synthesized over $\mathrm{Ni}$ nanoparticles in acetylene pyrolysis at $415{ }^{\circ} \mathrm{C}$. If the decomposition temperature was changed from 415 to $425^{\circ} \mathrm{C}$, CNCs production was $c a .3 .705 \mathrm{~g}$, corresponding to a yield of $c a .18,759.8 \%$, much higher than that of plait-like CNCs synthesized at $415{ }^{\circ} \mathrm{C}$. Similar to the case of synthesis at $415{ }^{\circ} \mathrm{C}$ (Figure $8 \mathrm{a}$ ), plait-like CNCs of high purity were obtained at $425{ }^{\circ} \mathrm{C}$, indicating that a change of pyrolysis temperature from 415 to $425{ }^{\circ} \mathrm{C}$ only increases the yield of plait-like CNCs but has little effect on the morphology of the CNCs sample. Moreover, we found that the pyrolysis temperature had a significant effect on microwave absorbing ability of carbon products. Compared to plait-like CNCs synthesized at $415^{\circ} \mathrm{C}$, the plait-like $\mathrm{CNCs}$ synthesized at $425^{\circ} \mathrm{C}$ showed a slight decrease in microwave absorbing ability.

In the synthesis of CNRs through the copyrolysis of $\mathrm{C}_{6} \mathrm{H}_{6}$ and $\mathrm{C}_{5} \mathrm{H}_{6}$ over cocatalysis of $\mathrm{Fe}$ and $\mathrm{Mg}$, Zou et al. [101] observed no activity below $400{ }^{\circ} \mathrm{C}$. At $500{ }^{\circ} \mathrm{C}$, short CNRs were produced. In the $600-700{ }^{\circ} \mathrm{C}$ range, longer CNRs were obtained in large quantity (ca. $90 \%$ yield). At $800{ }^{\circ} \mathrm{C}$, carbon particles were formed. Over $\mathrm{Ni}$ nanoparticles derived from sol-gel synthesis followed by hydrogen reduction, we synthesized CNRs (0.386 g) composed of carbon nanoflakes through the catalytic decomposition of benzene at temperature as low as $350{ }^{\circ} \mathrm{C}$ [192]. The yield of CNRs was ca. 1,537\%. There were nanorods of several microns in length and 200-400 nm in diameter (Figure 16). In Figure $16 \mathrm{~b}$, one can observe that the CNRs are composed of nanoflakes. It is known that interaction between graphitic layers is weak, and rupture of this kind of CNRs should be easy. We found "clear-cut" ends of CNRs different from those of CNTs, CNCs, and CNFs, and attributed the phenomenon to the fracture of flake-composed CNRs. Based on the FE-SEM images, we estimated a CNR selectivity of ca. $90 \%$; the rest are coiled nanowires and nanotubes of irregular morphology. When the decomposition temperature was $460{ }^{\circ} \mathrm{C}$, ca. $1.103 \mathrm{~g}$ of CNRs was collected, corresponding to ca. $4,579 \%$ yield of CNRs, much higher than that of CNRs obtained at $350{ }^{\circ} \mathrm{C}$. With a change of decomposition temperature from 350 to $460{ }^{\circ} \mathrm{C}$, there was an increase of CNR yield and a change in CNR morphology: the nanorods of CNRs obtained at $460{ }^{\circ} \mathrm{C}$ became curly in shape and bigger in 
diameter (ca. $500 \mathrm{~nm}$ ). A closer TEM investigation revealed that the curly nanorods were also composed of carbon nanoflakes. However, at $550{ }^{\circ} \mathrm{C}$, the majority of carbon species were MWNTs with inner diameter ca. $5 \mathrm{~nm}$ and outer diameter ranging from 15 to $40 \mathrm{~nm}$; the selectivity to CNTs was high, up to $c a$. $88 \%$. All the results demonstrated that the reaction temperature is an important factor in CNR formation.

Figure 16. (a) Low and (b) high magnification of FE-SEM images of samples synthesized at $350{ }^{\circ} \mathrm{C}$. The arrows indicate the "clear-cut" ends of CNRs [192].

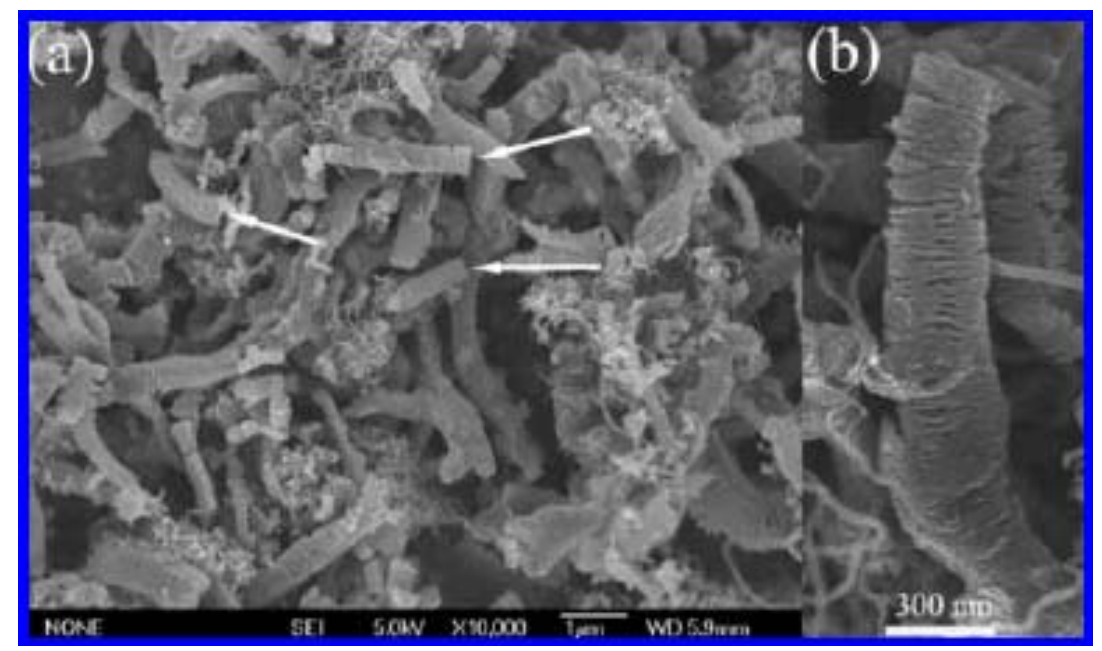

\subsection{Extra Effects}

Many studies revealed that carbon source $[180,193,194]$ and added gas such as $\mathrm{H}_{2} \mathrm{~S}$ and thiophene [195-197] are factors that influence the yield and quality of final products. The most widely used carbon sources are acetylene, methane, ethylene, ethanol, benzene and toluene. Due to the thermodynamic properties and chemical structures of the organic molecules, the hydrocarbon intermediates generated on catalyst surface have a significant effect on the morphology of final products. Using methane, hexane, cyclohexane, benzene, naphthalene and anthracene as carbon source in the synthesis of CNTs over MgO-supported Fe catalyst $\left(500-850{ }^{\circ} \mathrm{C}\right)$, Li et al. [198] came to the conclusion that chemical structures rather than thermodynamic properties of hydrocarbons determine the morphology of products. Also, it was found that aromatic molecules are better for the growth of SWNTs, whereas the use of aliphatic molecules usually result in the formation of MWNTs or species with non-tubular structures. Using chlorinated benzene, $\mathrm{C}_{6} \mathrm{H}_{6-\mathrm{x}} \mathrm{Cl}_{\mathrm{x}}(\mathrm{x}=0-3)$, as carbon precursors, $\mathrm{Lv}$ et al. [199] produced permalloy (FeNi) nanowires micrometer in length inside thin-walled CNTs. They found that FeNi content and hollow degrees of CNTs increased in the order of $\mathrm{C}_{6} \mathrm{H}_{6}(\mathrm{x}=0)<\mathrm{C}_{6} \mathrm{H}_{5} \mathrm{Cl}$ $(\mathrm{x}=1)<\mathrm{C}_{6} \mathrm{H}_{4} \mathrm{Cl}_{2} \mathrm{DCB}(\mathrm{x}=2)<\mathrm{C}_{6} \mathrm{H}_{3} \mathrm{Cl}_{3}(\mathrm{x}=3)$. The authors attributed the formation of thin-walled CNTs to "carbon-rich and hydrogen-deficient" condition generated as a result of $\mathrm{Cl}$ combination with reactive hydrogen. Under such condition, the formation of $\mathrm{sp}^{2}$-like graphitic structure that is critical for the formation of thin-walled CNTs became favorable.

Moreover, gas such as $\mathrm{H}_{2} \mathrm{~S}$ and thiophene is often added to the carbon source during pyrolysis to optimize the quality of carbon nanomaterials. Generally, CNTs prepared through the pyrolysis of hydrocarbon source at high temperatures $\left(500\right.$ to $\left.1000{ }^{\circ} \mathrm{C}\right)$ have straight or randomly curled 
morphology. In most cases, CNCs were reported as a by-product. In the past few years, efforts have been put in to synthesize regular CNCs in high selectivity. Motojima and coworkers [200,201] detected regular coiled carbon fibers of micron size in CCVD processes. In the experiments, carbon atoms coming from the pyrolysis of acetylene or propane deposited on micron-sized Ni particles in the presence of thiophene. Recently, using commercial acetylene as carbon source, nickel plate as catalyst and phosphorous compound as additive, Zhao and Shen [202] synthesized CNCs with high selectivity. Adding a small amount of $\mathrm{H}_{2} \mathrm{~S}$ into acetylene, Chen and coworkers [203] synthesized twisting CNCs in high selectivity over $\mathrm{Ni} / \mathrm{Al}_{2} \mathrm{O}_{3}$ at $760{ }^{\circ} \mathrm{C}$. Again by the addition of a small amount of $\mathrm{H}_{2} \mathrm{~S}$ in acetylene, the authors synthesized CMCs over $\mathrm{Ni}$ in the $700-800{ }^{\circ} \mathrm{C}$ range [204]. Overall, the selectivity to carbon coils could be greatly enhanced by adding sulfur or phosphorus into the carbon source.

\section{Conclusions}

Since the landmark paper of Ijima published in 1991, carbon nanotubes are designated as one of the most attractive materials for a wide range of potential applications. In the past two decades, there have been advances in the production of carbon nanotubes in terms of quality as well as quantity. In the course of it, carbon nanomaterials of other structures, such as carbon nanocoils, carbon nanorods, carbon nanobelts and grapheme, were detected and investigated. Contributions have been made toward the mass synthesis and understanding of magnetic and microwave absorption properties of carbon nanomaterials. It is observed that by means of CVD over catalysts made of transition metals, it is possible to selectively generate carbon nanomaterials in high quantity. Among the catalysts, those based on iron, cobalt, nickel and their alloys perform well. As carbon sources, acetylene, methane, ethanol, ethylene, benzene and toluene are widely used. It is known that factors such as reactor design, preparation method of catalysts, catalyst category, support, catalyst additive, precursor reduction temperature, pyrolysis temperature, carbon source, additive to carbon source, and reaction time have impact on the growth of carbon nanomaterials. By means of careful manipulation of these factors, one can selectively produce a desired carbon nanomaterial in large scale. For wide utilization of carbon nanomaterials, research on this aspect remains challenging.

\section{Acknowledgements}

This work was supported by the National Laboratory of Solid State Microstructures of Nanjing University (2010ZZ18), the National High Technology Research and Development Program of China (Grant No. 2007AA021805), and the National Key Project for Basic Research (Grant Nos. 2005CB623605 and 2010CB923402), China.

\section{References and Notes}

1. Iijima, S. Helical microtubules of graphitic. Carbon 1991, 354, 56-58.

2. Ebbesen, T.W.; Lezec, H.J.; Hiura, H.; Bennett, J.M.; Ghaemi, H.F.; Thio, T. Electrical conductivity of individual carbon nanotubes. Nature 1996, 382, 54-56.

3. De Heer, W.A.; Bacsa, W.S.; Chatelain, A.; Gergin, T.; Humphrey-Baker, R.; Forro, L.; Ugarte, D. Aligned carbon nanotube films-production and optical and electronic-properties. Science 1995, $268,845-847$. 
4. Delaney, P.; Choi, H.J.; Ihm, J.; Cohen, M.L. Broken symmetry and pseudogaps in ropes of carbon nanotubes. Nature 1998, 391, 466-468.

5. Fan, S.S.; Chapline, M.G.; Franklin, N.R.; Tomber, T.W.; Cassell, A.M.; Dai, H.J. Self-oriented regular arrays of carbon nanotubes and their field emission properties. Science 1999, 283, 512-514.

6. Kiang, C.H.; Choi, J.S.; Tran, T.T.; Bacher, A.D. Molecular nanowires of $1 \mathrm{~nm}$ diameter from capillary filling of single-walled carbon nanotubes. J. Phy. Chem. B 1999, 103, 7449-7451.

7. Tans, S.J.; Verschueren, A.R.M.; Dekker, C. Room-temperature transistor based on a single carbon nanotube. Nature 1998, 393, 49-52.

8. Yao, Z.; Postma, H.W.C.; Balents, L.; Dekker, C. Carbon nanotube intramolecular junctions. Nature 1999, 402, 273-276.

9. Rueckes, T.; Kim, K.; Joselevich, E.; Tseng, G.Y.; Cheung, C.L.; Lieber, C.M. Carbon nanotube-based nonvolatile random access memory for molecular computing. Science 2000, 289, 94-97.

10. Wong, S.S.; Joselevich, E.; Wooley, A.T.; Cheung, C.L.; Lieber, C.M. Covalently functionalized nanotubes as nanometre-sized probes in chemistry and biology. Nature 1998, 394, 52-55.

11. Hafner, J.H.; Cheung, C.L.; Lieber, C.M. Direct growth of single-walled carbon nanotube scanning probe microscopy tips. J. Am. Chem. Soc. 1999, 121, 9750-9751.

12. Dai, H.J. Carbon nanotubes: opportunities and challenges. Surf. Sci. 2002, 500, 218-241.

13. Dillon, A.C.; Jones, K.M.; Bekkedahl, K.K.; Kiang, C.H.; Bethune, D.S.; Heben, M.J. Storage of hydrogen in single-walled carbon nanotubes. Nature 1997, 386, 377-379.

14. Vigolo, B.; Penicaud, A.; Coulon, C.; Sauder, C.; Pailler, R.; Journet, C.; Bernier, P.; Poulin, P. Macroscopic fibers and ribbons of oriented carbon nanotubes. Science 2000, 290, 1331-1334.

15. Takagi, D.; Homma, Y.; Hibino, H.; Suzuki, S.; Kobayashi Y. Single-walled carbon nanotube growth from highly activated metal nanoparticles. Nano Lett. 2006, 6, 2642-2645.

16. Ni, C.; Bandaru, P.R. Enhanced optical absorption cross-section characteristics of multi-wall carbon nanotubes. Carbon 2009, 47, 2898-2903.

17. Cao, Q.; Rogers, J.A. Ultrathin films of single-walled carbon nanotubes for electronics and sensors: a review of fundamental and applied aspects. Adv. Mater. 2009, 21, 29-53.

18. Avouris, P. Molecular electronics with carbon nanotubes. Acc. Chem. Res. 2002, 35, 1026-1034.

19. Ouyang, M.; Huang, J.L.; Lieber, C.M. Fundamental electronic properties and applications of single-walled carbon nanotubes. Acc. Chem. Res. 2002, 35, 1018-1025.

20. Popov, V.N. Carbon nanotubes: properties and application. Mater. Sci. Eng. R 2004, 43, 61-102.

21. Charlier, J.C.; Blase, X.; Roche, S. Electronic and transport of nanotubes. Rev. Mod. Phys. 2007, 79, 677-732.

22. Yamamoto, T.; Watanabe, K.; Hernandez, E.R.; Mechanical properties, thermal stability and heat transport in carbon nanotubes. Carbon Nanotubes 2008, 111, 165-194.

23. Tans, S.J.; Devoret, M.H.; Dai, H.J.; Thess, A.; Smalley, R.E.; Geerligs, L.J.; Dekker, C. Individual single-wall carbon nanotubes as quantum wires. Nature 1997, 386, 474-477.

24. Matsuoka, K.; Kataura, H.; Shiraishi, M. Ambipolar single electron transistors using side-contacted single-walled carbon nanotubes. Chem. Phys. Lett. 2006, 417, 540-544.

25. Babic, B.; Iqbal, M.; Schonenberger, C. Ambipolar field-effect transistor on as-grown single-wall 
carbon nanotubes. Nanotechnology 2003, 14, 327-331.

26. Li, C.Y.; Chou, T.W. Strain and pressure sensing using single-walled carbon nanotubes. Nanotechnology 2004, 15, 1493-1496.

27. Thess, A.; Lee, R.; Nikolaev, P.; Dai, H.J.; Petit, P.; Robert. J.; Xu, C.H.; Lee, Y.H.; Kim, S.G.; Rinzler, A.G.; Colbert, D.T.; Scuseria, G.E;; Tomanek, D.; Fischer, J.E.; Smalley, R.E. Crystalline ropes of metallic carbon nanotubes. Science 1996, 273, 483-487.

28. Journet, C.; Maser, W.K.; Bernier, P.; Loiseau, A.; delaChapelle, M.L.; Lefrant, S.; Deniard, P.; Lee, P.; Fischer, J.E. Large-scale production of single-walled carbon nanotubes by the electric-arc technique. Nature 1997, 388, 756-758.

29. Grüneis, A.; Kramberger, C.; Grimm, D.; Gemming, T.; Rümmeli, M.H.; Barreiro, A.; Ayala, P.; Pichler, T.; Schaman, C.; Kuzmany, H.; Schumann, J.; Büchner, B. Eutectic limit for the growth of carbon nanotubes from a thin iron film by chemical vapor deposition of cyclohexane. Chem. Phys. Lett. 2006, 425, 301-305.

30. Meyyappan, M.; Delzeit, L.; Cassell, A.; Hash, D. Carbon nanotube growth by PECVD: a review. Plasma Sources Sci. Technol. 2003, 12, 205-216.

31. Setton, R.; Setton, N. Carbon nanotubes: III. Toroidal structures and limits of a model for the construction of helical and S-shaped nanotubes. Carbon 1997, 35, 497-505.

32. Chen, Y.; Liu, C.; Du, J.H.; Cheng, H.M. Preparation of carbon microcoils by catalytic decomposition of acetylene using nickel foam as both catalyst and substrate. Carbon 2005, 43, 1874-1878.

33. Fonseca, A.; Hernadi, K.; Nagy, J.B.; Lambin, Ph.; Lucas, A.A. Model structure of perfectly graphitizable coiled nanotubes. Carbon 1995, 33, 1759-1775.

34. Qi, X.S.; Zhong, W.; Deng, Y.; Au, C.T.; Du, Y.W. Synthesis of helical carbon nanotubes, worm-like carbon nanotubes and nanocoils at $450{ }^{\circ} \mathrm{C}$ and their magnetic properties. Carbon 2010 , 48, 365-376.

35. Chen, X.Q.; Zhang, S.L.; Dikin, D.A.; Ding, W.Q.; Ruoff, R.S.; Pan. L.J. Mechanics of a carbon nanocoil. Nano Lett. 2003, 3, 1299-304.

36. Chen, X.Q.; Motojima, S.; Iwanaga, H. Carbon coatings on carbon micro-coils by pyrolysis of methane and their properties. Carbon 1999, 37, 1825-1831.

37. Yan, S.M.; Chen, X.Q.; Motojima, S. Tactile sensing properties of protein-like single-helix carbon microcoils. Carbon 2006, 44, 3352-3355.

38. Akagi, K.; Tamura, R.; Tsukada, M.; Itoh, S.; Ihara, S. Electronic-structure of helically coiled cage of graphitic carbon. Phys. Rev. Lett. 1995, 74, 2307-2310.

39. Ivanov, V.; Nagy, J.B.; Lambin, Ph.; Lucas, A.; Zhang, X.B.; Zhang, X.F.; Bernaerts, D.; Van Tendeloo, G.; Amelinckx, S.; Landuyt, J.V. The study of carbon nanotubules produced by catalytic method. Chem. Phys. Lett. 1994, 223, 329-335.

40. Hernadi, K.; Thien-Nga, L.; Forro, L. Growth and microstructure of catalytically produced coiled carbon nanotubes. J. Phys. Chem. B 2001, 105, 12464-12468.

41. Zhang, X.B.; Zhang, X.F.; Bernaerts, D.; Tendeloo, G.V.; Amelinckx, S.; Landuyt, J.V.; Ivanov, V.; Nagy, J.B.; Lambin, Ph.; Lucas, A. The texture of catalytically grown coil-shaped carbon nanotubules. Europhys. Lett. 1994, 27, 141-146. 
42. Amelinckx, S.; Zhang, X.B.; Bernaerts, D.; Zhang, X.F.; Ivanov, V.; Nagy, J.B. A formation mechanism for catalytically grown helix-shaped graphite nanotubes. Science 1994, 265, 635-639.

43. Wen, Y.K.; Shen, Z.M. Synthesis of regular coiled carbon nanotubes by Ni-catalyzed pyrolysis of acetylene and a growth mechanism analysis. Carbon 2001, 39, 2369-2374.

44. Bajpai, V.; Dai, L.M.; Ohashi, T. Large-scale synthesis of perpendicularly aligned helical carbon nanotubes. J. Am. Chem. Soc. 2004, 126, 5070-5071.

45. Lu, M.; Liu, W.M.; Guo, X.Y.; Li, H.L. Coiled carbon nanotubes growth via reduced-pressure catalytic chemical vapor deposition. Carbon 2004, 42, 805-811.

46. Hou, H.Q.; Jun, Z.; Weller, F.; Greiner, A. Large-scale synthesis and characterization of helically coiled carbon nanotubes by use of $\mathrm{Fe}(\mathrm{CO})_{5}$ as floating catalyst precursor. Chem. Mater. 2003, 15, 3170-3175.

47. Bai, J.B. Growth of nanotubes/nanofibers coils by CVD on an alumina substrate. Mater. Lett. 2003, 57, 2629-2633.

48. Xie, J.N.; Mukhopadyay, K.; Yadev, J.; Varadan, V.K. Catalytic chemical vapor deposition synthesis and electron microscopy observation of coiled carbon nanotubes. Smart. Mater. Struct. 2003, 12, 744-748.

49. Zhong, D.Y.; Liu, S.; Wang, E.G. Patterned growth of coiled carbon nanotubes by a template-assisted technique. Appl. Phys. Lett. 2003, 83, 4423-4425.

50. Gao, R.P.; Wang, Z.L.; Fan, S.S. Kinetically controlled growth of helical and zigzag shapes of carbon nanotubes. J. Phys. Chem. B 2000, 104, 1227-1234.

51. Luo, T.; Liu, J.W.; Chen, L.Y.; Zeng, S.Y.; Qian, Y.T. Synthesis of helically coiled carbon nanotubes by reducing ethyl ether with metallic zinc. Carbon 2005, 43, 755-759.

52. Motojima, S.; Kawaguchi, M.; Nozaki, K.; Iwanaga, H. Growth of regularly coiled carbon filaments by $\mathrm{Ni}$ catalyzed pyrolysis of acetylene, and their morphology and extension characteristic. Appl. Phys. Lett. 1990, 56, 321-323.

53. Yang, S.M.; Hasegawa, M.; Chen, X.Q.; Motojima, S. Synthesis and morphology of carbon microcoils produced using methane as a carbon source. Carbon 2007, 45, 1592-1595.

54. Pan, L.J.; Zhang, M.; Nakayama, Y. Growth mechanism of carbon nanocoils. J. Appl. Phys. 2002, 91, 10058-10061.

55. Duesberg, G.S.; Graham, A.P.; Kreupl, F.; Liebau, M.; Seidel, R.; Unger, E.; Hoenlein, W. Ways towards the scaleable integration of carbon nanotubes into silicon based technology. Diamond Relat. Mater. 2004, 13, 354-361.

56. Korneva, G.; Ye, H. H.; Gogotsi, Y.; Halverson, D.; Friedman, G.; Bradley, J. C.; Kornev, K. G. C. 2005, 5, 879 .

57. Tang, N.J.; Zhong, W.; Au, C.T.; Gedanken, A.; Yang, Y.; Du, Y.W. Large-scale synthesis, annealing, purification, and magnetic properties of crystalline helical carbon nanotubes with symmetrical structures. Adv. Funct. Mater. 2007, 17, 1542-1550.

58. Karwa, M.; Iqbal, Z.; Mitra, S. Scaled-up self-assembly of carbon nanotubes inside long stainless steel tubing. Carbon 2006, 44, 1235-1242.

59. Yang, Q.; Tang, Y.; Yang, S.L.; Li, Y.S.; Hirose, A. Simultaneous growth of diamond thin films and carbon nanotubes at temperatures $<=550^{\circ} \mathrm{C}$. Carbon 2008, 46, 589-595. 
60. Tang, N.J.; Zhong, W.; Gedanken, A.; Du, Y.W. High magnetization helical carbon nanofibers produced by nanoparticle catalysis. J. Phys. Chem. B 2006, 110, 11772-11774

61. Tang, N.J.; Yang, Y.; Lin, K.J.; Zhong, W.; Au, C.T.; Du, Y.W. Synthesis of plait-like carbon nanocoils in ultrahigh yield, and their microwave absorption properties. J. Phys. Chem. C 2008, 112, 10061-10067.

62. Tang, N.J.; Zhong, W.; Au, C.T.; Yang, Y.; Han, M.G.; Lin, K.J.; Du, Y.W. Synthesis, microwave electromagnetic, and microwave absorption properties of twin carbon nanocoils J. Phys. Chem. C 2008, 112, 19316-19323.

63. Arya, V.P.; Prasad, V.; Kumar, P.S.A. Magnetic properties of iron particles embedded in multiwall carbon nanotubes. J. Nanosci. Nanotechno. 2009, 9, 5406-5410.

64. Aguilo-Aguayo, N.; Castano-Bernal, J.L.; Garcia-Cespedes, J.; Bertran, E. Magnetic response of CVD and PECVD iron filled multi-walled carbon nanotubes. Diamond Relat. Mater. 2009, 18, 953-956.

65. Misra, A.; Daraio, C. Sharp carbon-nanotube tips and carbon-nanotube soldering irons. Adv. Mater. 2009, 21, 2305-2308.

66. Radhakrishnan, J.K.; Pandian, P.S.; Padaki, V.C.; Bhusan, H.; Rao, K.U.B.; Xie, J.; Abraham, J.K.; Varadan, V.K. Growth of multiwalled carbon nanotube arrays by chemical vapor deposition over iron catalyst and the effect of growth parameters. Appl. Surf. Sci. 2009, 255, 6325-6334.

67. Liu, Q.F.; Ren, W.C.; Chen, Z.G.; Liu, B.L.; Yu, B.; Li, F.; Cong, H.T.; Cheng, H.M. Direct synthesis of carbon nanotubes decorated with size-controllable Fe nanoparticles encapsulated by graphitic layers. Carbon 2008, 46, 1417-1423.

68. Yuan, D.N.; Ding, L.; Chu, H.B.; Feng, Y.Y.; McNicholas, T.P.; Liu, J. Horizontally aligned single-walled carbon nanotube on quartz from a large variety of metal catalysts. Nano Lett. 2008, 8, 2576-2579.

69. Kakehi, K.; Noda, S.; Maruyama, S.; Yamaguchi, Y. Individuals, grasses, and forests of singleand multi-walled carbon nanotubes grown by supported Co catalysts of different nominal thicknesses. Appl. Surf. Sci. 2008, 254, 6710-6714.

70. Zheng, Z.; Xu, B.; Huang, L.; He, L.; Ni, X.M. Novel composite of Co/carbon nanotubes: Synthesis, magnetism and microwave absorption properties. Solid. State. Sci. 2008, 3, 316-320.

71. Kakehi, K.; Noda, S.; Maruyama, S.; Yamaguchi, Y. Growth valley dividing single- and multi-walled carbon nanotubes: Combinatorial study of nominal thickness of Co catalyst. Jpn. J. Appl. Phys. 2008, 47, 1961-1965.

72. Khavrus, V.O.; Lemesh, N.V.; Gordijchuk, S.V.; Tripolsky, A.I.; Ivashchenko, T.S.; Biliy, M.M.; Strizhak, P.E. Chemical catalytic vapor deposition (CCVD) synthesis of carbon nanotubes by decomposition of ethylene on metal (Ni, Co, Fe) nanoparticles. React. Kinet. Catal. L. 2008, 93, 295-303.

73. Wei, S.; Kang, W.P.; Davidson, J.L.; Huang, J.H. Aligned carbon nanotubes fabricated by thermal CVD at atmospheric pressure using Co as catalyst with $\mathrm{NH}_{3}$ as reactive gas. Diamond Relat. Mater. 2006, 15, 1828-1833.

74. Kozhuharova, R.; Ritschel, M.; Elefant, D.; Graff, A.; Leonhardt, A.; Monch, I.; Muhl, T.; Groudeva-Zotova, S.; Schneider, C.M. Well-aligned Co-filled carbon nanotubes: preparation and magnetic properties. Appl. Surf. Sci. 2004, 238, 355-359. 
75. Zaretskiy, S.N.; H6ong, Y.K.; Ha, D.H.; Yoon, J.H.; Cheon, J.; Koo, J.Y. Growth of carbon nanotubes from $\mathrm{Co}$ nanoparticles and $\mathrm{C}_{2} \mathrm{H}_{2}$ by thermal chemical vapor deposition. Chem. Phys. Lett. 2003, 372, 300-305.

76. Kar, K.K.; Rahaman, A.; Agnihotri, P.; Sathiyamoorthy, D. Synthesis of carbon nanotubes on the surface of carbon fiber/fabric by catalytic chemical vapor deposition and their characterization. Fuller Nanotub. Car. N. 2009, 17, 209-229.

77. Feng, H.; Ma, J.; Hu, Z. Six-membered-ring-based radical mechanism for catalytic growth of carbon nanotubes with benzene precursor. J. Phys. Chem. C 2009, 113, 6495-16502.

78. Khavrus, V.O.; Lemesh, N.V.; Gordijchuk, S.V.; Tripolsky, A.I.; Ivashchenko, T.S.; Biliy, M.M.; Strizhak, P.E. Chemical catalytic vapor deposition (CCVD) synthesis of carbon nanotubes by decomposition of ethylene on metal (Ni, Co, Fe) nanoparticles. React. Kinet. Catal. L. 2008, 93, 295-303.

79. Guan, L.H.; Shi, Z.J.; Li, H.J.; You, L.P.; Gu, Z.N. Super-long continuous Ni nanowires encapsulated in carbon nanotubes. Chem. Commun. 2004, 17, 1988-1989.

80. Choi, J.H.; Lee, T.Y.; Choi, S.H.; Han, J.H.; Yoo, J.B.; Park, C.Y.; Jung, T.; Yu, S.G.; Yi, W.; Han, I.T.; Kim, J.M. Control of carbon nanotubes density through Ni nanoparticle formation using thermal and $\mathrm{NH}_{3}$ plasma treatment. Diamond Relat. Mater. 2003, 12, 794-798.

81. Gozzi, D.; Latini, A.; Capannelli, G.; Canepa, F.; Napoletano, M.; Cimberle, M.R.; Tropeano, M. Synthesis and magnetic characterization of Ni nanoparticles and Ni nanoparticles in multiwalled carbon nanotubes. J. Alloy. Comp. 2006, 419, 32-39.

82. Tsuchiya, N.; Ogino, T. Morphology of carbon nanostructures in alcohol chemical vapor deposition. Jpn. J. Appl. Phys. 2007, 46, 6091-6094.

83. Lv, R.T.; Kang, F.Y.; Wang, W.X.; Wei, J.Q.; Gu, J.L.; Wang, K.L.; Wu, D.H. Effect of using chlorine-containing precursors in the synthesis of FeNi-filled carbon nanotubes. Carbon 2007, 45 , $1433-1438$.

84. Jourdain, V.; Paillet, M.; Almairac, R.; Loiseau, A.; Bernier, P. Relevant synthesis parameters for the sequential catalytic growth of carbon nanotubes. J. Phys. Chem. B 2005, 109, 1380-1386.

85. Lv, R.T.; Kang, F.Y.; Gu, J.L.; Gui, X.C.; Wei, J.Q.; Wang, K.L.; Wu, D.H. Carbon nanotubes filled with ferromagnetic alloy nanowires: Lightweight and wide-band microwave absorber. Appl. Phys. Lett. 2008, 93, 223105:1-223105:3.

86. Buang, N.A.; Abd Majid, Z.; Sulaiman, Y.; Sanip, S.M.; Ismail, A.F. Effect of addition of Ni metal catalyst onto the Co and Fe supported catalysts for the formation of carbon nanotubes. $J$. Porous Mat. 2006, 13, 331-334.

87. Lv, R.T.; Kang, F.Y.; Cai, D.Y.; Wang, C.; Gu, J.L.; Wang, K.L.; Wu, D.H. Long continuous FeNi nanowires inside carbon nanotubes: Synthesis, property and application. J. Phys. Chem. Solids 2008, 69, 1213-1217.

88. Esconjauregui, S.; Whelan, C.M.; Maex, K. The reasons why metals catalyze the nucleation and growth of carbon nanotubes and other carbon nanomorphologies. Carbon 2009, 47, 659-669.

89. Seidel, R.; Duesberg, G.S.; Unger, E.; Graham, A.P.; Liebau, M.; Kreupl, F. Chemical vapor deposition growth of single-walled carbon nanotubes at $600{ }^{\circ} \mathrm{C}$ and a simple growth model. $J$. Phys. Chem. B 2004, 108, 1888-1893.

90. Dong, L.; Jiao, J.; Pan, C.; Tuggle, D.W. Effects of catalysts on the internal structures of carbon 
nanotubes and corresponding electron field-emission properties Appl. Phys. A 2004, 78, 9-14.

91. Luo, G.H.; Li, Z.F.; Wei, F.; Xiang, L.; Deng, X.Y.; Jin, Y. Catalysts effect on morphology of carbon nanotubes prepared by catalytic chemical vapor deposition in a nano-agglomerate bed. Phys. B 2002, 323, 314-317.

92. Zhang, Z.J.; Shakerzadeh, M.; Tay, B.K.; Li, X.C.; Tan, C.W.; Lin, L.F.; Guo, P.S.; Feng, T.; Sun, Z. Fabrication of aligned carbon nanotubes on $\mathrm{Cu}$ catalyst by dc plasma-enhanced catalytic decomposition. Appl. Surf. Sci. 2009, 255, 6404-6407.

93. Luo, C.X.; Liu, L.; Jiang, K.L.; Zhang, L.; Li, Q.Q.; Fan, S.S. Growth mechanism of Y-Junctions and related carbon nanotube junctions synthesized by Au-catalyzed chemical vapor deposition. Carbon 2008, 46, 440-444.

94. Zhang, Z.J.; Chua, D.H.C.; Gao, Y.; Zhang, Y.P.; Tang, Z.; Tay, B.K.; Feng, T.; Sun, Z.; Chen, Y.W. Field-emission properties of carbon nanotubes grown using $\mathrm{Cu}-\mathrm{Cr}$ catalysts. J. Vac. Sci. Technol. B 2009, 27, 41-46.

95. Lee, C.J.; Park, J.; Kim, J.M.; Huh, Y.; Lee, J.Y.; No, K.S. Low-temperature growth of carbon nanotubes by thermal chemical vapor deposition using $\mathrm{Pd}, \mathrm{Cr}$, and $\mathrm{Pt}$ as co-catalyst. Chem. Phys. Lett. 2000, 327, 277-283.

96. Zhang, Y.H.; Qin, Y.H.; Sun, X.; Zhang, J.; Jing, C.B. Synthesis of carbon nanotube using cesium carbonate catalyst by chemical vapor deposition. Mater. Lett. 2008, 62, 3776-3778.

97. Zhang, Y.H.; Sun, X. Synthesis of carbon nanofibers and foam by catalytic chemical vapor deposition using a water-soluble alkali salt catalyst. Adv. Mater. 2007, 19, 961-964.

98. Klinke, C.; Bonard, J.M.; Kern, K. Comparative study of the catalytic growth of patterned carbon nanotube films. Surf. Sci. 2001, 492, 195-201.

99. Lee, C.J.; Park, J.; Yu, J.A. Catalyst effect on carbon nanotubes synthesized by thermal chemical vapor deposition. Chem. Phys. Lett. 2002, 360, 250-255.

100. Chen, X.C.; Wang, H.; He, J.H. Synthesis of carbon nanotubes and nanospheres with controlled morphology using different catalyst precursors. Nanotechnology 2008, 19, 325607/1-6.

101. Zou, G.F.; Lu, J.; Wang, D.B.; Xu, L.Q.; Qian, Y.T. High-yield carbon nanorods obtained by a catalytic copyrolysis process. Inorg. Chem. 2004, 43, 5432-5435.

102. Yang, S.M.; Chen, X.Q.; Motojima, S.; Iwanaga, H. The phenomenon of changing coiling-chirality in carbon nanocoils obtained by catalytic pyrolysis of acetylene with various catalysts. J. Nanosci. Nanotechno. 2004, 4, 167-175.

103. Calderon-Moreno, J.M.; Labarta, A.; Batlle, X.; Pradell, T.; Crespo, D.; Binh, V.T. Magnetic properties of dense carbon nanospheres prepared by chemical vapor deposition. Chem. Phys. Lett. 2007, 447, 295-299.

104. Xi, G.C.; Zhang, M.; Ma, D.; Zhu, Y.C.; Zhang, H.B.; Qian, Y.T. Controlled synthesis of carbon nanocables and branched-nanobelts. Carbon 2006, 44, 734-741.

105. Motojima, S.; Chen, X.; Yang, S.; Hasegawa, M. Properties and potential applications of carbon microcoils/nanocoils. Diamond Relat. Mater. 2004, 13, 1989-1992.

106. Yang, S.; Chen, X.; Motojima, S. Morphology of the growth tip of carbon microcoils/nanocoils. Diamond Relat. Mater. 2004, 13, 2152-2155.

107. Zhao, D.L.; Shen, Z.M. Preparation and microwave absorption properties of carbon nanocoils. Mater. Lett. 2008, 62, 3704-3706. 
108. Kuzuya, C.; In-Hwang, W.; Hirako, S.; Hishikawa, Y.; Motojima, S. Preparation, morphology, and growth. mechanism of carbon nanocoils. Chem. Vapor. Depos. 2002, 8, 57-62.

109. Chen, X.Q.; Hasegawa, M.; Yang, S.M.; Nitta, Y.; Katsuno, T.; Motojima, S. Preparation of carbon microcoils by catalytic methane hot-wire CVD process. Thin Solid Films 2008, 516, 714-717.

110. Su, M.; Zheng, B.; Liu, J. A scalable CVD method for the synthesis of single-walled carbon nanotubes with high catalyst producitivity. Chem. Phys. Lett. 2000, 322, 321-326.

111. Kong, J.; Cassell, A.; Dai, H. Chemical vapor deposition of methane for single-walled carbon nanotubes. Chem. Phys. Lett. 1998, 292, 567-574.

112. Planeix, J.M.; Coustel, N.; Coq, B.; Brotons, V.; Kumbhar, P.S.; Dutartre, R.; Geneste, P.; Bernier, P.; Ajayan, P.M. Application of carbon nanotubes as supports in heterogeneous catalysis. J. Am. Chem. Soc. 1994, 116, 7935-7936.

113. Gao, R.; Tan, C.D.; Baker, R.T.K. Ethylene hydroformylation on graphite nanofiber supported rhodium catalysts. Catal. Today 2001, 65, 19-29.

114. Vieira, R.; Pham-Huu, C.; Keller, N.; Ledoux, M.J. New carbon nanofiber/graphite felt composite for use as a catalyst support for hydrazine catalytic decomposition. Chem. Commun. 2002, 9, 954-955.

115. Chen, P.; Zhang, H.B.; Lin, G.D.; Hong, Q.; Tsai, K.R. Growth of carbon nanotubes by catalytic decomposition of $\mathrm{CH}_{4}$ or $\mathrm{CO}$ on a Ni-MgO catalyst. Carbon 1997, 35, 1495-1501.

116. Bacsa, R.R.; Laurent, C.; Peigney, A.; Bacsa, W.S.; Vaugien, T.; Rousset, A. High specific surface area carbon nanotubes from catalytic chemical vapor deposition process. Chem. Phys. Lett. 2000, 323, 566-571.

117. Pinheiro, J.P.; Schouler, M.C.; Gadelle, P. Nanotubes and nanofilaments from carbon monoxide disproportionation over $\mathrm{Co} / \mathrm{MgO}$ catalysts I. Growth versus catalyst state. Carbon 2003, 41, 2949-2959.

118. Ivanov, V.; Nagy, J.B.; Lambin, P.; Lucas, A.; Zhang, X.F.; Bernaerts, D.; Vantendelod, G.; Amelinckx, S.; Vanlanduyt, J. The study of carbon nanotubules produced by catalytic method. Chem. Phys. Lett. 1994, 223, 329-335.

119. Hernadi, K.; Fonseca, A.; Nagy, J.B.; Bernaerts, D.; Fudala, A.; Lucas, A.A. Catalytic synthesis of carbon nanotubes using zeolite support. Zeolites 1996, 17, 416-423.

120. Ros, T.G.; Keller, D.E.; van Dillen, A.J.; Geus, J.W.; Koningsberger, D.C. Preparation and activity of small rhodium metal particles on fishbone carbon nanofibers. J. Catal. 2002, 211, 85-102.

121. Häffner, M.; Haug, A.; Weitz, R.T.; Fleischer, M.; Burghard, M.; Peisert, H.; Chassé.; Kern, D.P. E-beam lithography of catalyst patterns for carbon nanotube growth on insulating substrates. Microelectron. Eng. 2008, 85, 768-773.

122. Fonseca, A.; Hernadi, K.; Nagy, J.B.; Bernaerts, D.; Lucas, A.A. Optimization of catalytic production and purification of buckytubes. J. Mol. Catal. A: Chem 1996, 107, 159-168.

123. Aexiadis, V.I.; Verykios, X.E. Influence of structural and preparation parameters of $\mathrm{Fe}_{2} \mathrm{O}_{3} / \mathrm{Al}_{2} \mathrm{O}_{3}$ catalysts on rate of production and quality of carbon nanotubes. Mater. Chem. Phys. 2009, 117, $528-535$. 
124. Avdeeva, L.B.; Kochubey, D.I.; Shaikhutdinov, S.K. Cobalt catalysts of methane decomposition: accumulation of the filamentous carbon. Appl. Catal. A: Gen 1999, 177, 43-51.

125. Reshetenko, T.V.; Avdeeva, L.B.; Ismagilov, Z.R.; Chuvilin, A.L.; Ushakov, V.A. Carbon capacious $\mathrm{Ni}-\mathrm{Cu}-\mathrm{Al}_{2} \mathrm{O}_{3}$ catalysts for high-temperature methane decomposition. Appl. Catal. A: Gen 2003, 247, 51-63.

126. Reshetenko, T.V.; Avdeeva, L.B.; Ismagilov, Z.R.; Chuvilin, A.L.; Fenelonov, V.B. Catalytic filamentous carbons-supported $\mathrm{Ni}$ for low-temperature methane decomposition. Catal. Today 2005, 102, 115-120.

127. Inoue, M.; Asai, K.; Nagayasu, Y.; Takane, K.; Iwamoto, S.; Yagasaki, E.; Ishii, K.I. Formation of multi-walled carbon nanotubes by Ni-catalyzed decomposition of methane at $600-750{ }^{\circ} \mathrm{C}$. Diamond Relat. Mater. 2008, 17, 1471-1475.

128. Yu, G.J.; Gong, J.L.; Zhu, D.Z.; He, S.X.; Cao, J.Q.; Zhu, Z.Y. Efficient synthesis of carbon nanotubes over rare earth zeolites by thermal chemical vapor deposition at low temperature. Diamond Relat. Mater. 2006, 15, 1261-1265.

129. Tang, T.; Chen, X.C.; Meng, X.Y.; Chen, H.; Ding, Y.P. Synthesis of multiwalled carbon nanotubes by catalytic combustion of polypropylene. Angew Chem. Int. Edit. 2005, 44, $1517-1520$.

130. Kim, H.S.; Kim, B.; Lee, B.; Chung, H.; Lee, C.J.; Yoon, H. G.; Kim, W. Synthesis of aligned few-walled carbon nanotubes on conductive substrates. J. Phys. Chem. C 2009, 113, 17983-17988.

131. Li, C.Y.; Zhu, H.W.; Suenaga, K.; Wei, J.Q.; Wang, K.L.; Wu, D.H. Diameter dependent growth mode of carbon nanotubes on nanoporous $\mathrm{SiO}_{2}$ substrates. Mater. Lett. 2009, 63, 1366-1369.

132. Lee, W.Y.; Lin, H.; Gu, L.; Leou, K.C.; Tsai, C.H. CVD catalytic growth of single-walled carbon nanotubes with a selective diameter distribution. Diamond Relat. Mater. 2008, 17, 66-71.

133. Landois, P.; Peigney, A.; Laurent, C.; Frin, L.; Datas, L.; Flahaut, E. CCVD synthesis of carbon nanotubes with W/Co-MgO catalysts. Carbon 2009, 47, 789-794.

134. Xu, Y.; Li, Z.R.; Dervishi, E.; Saini, V.; Cui, J.B.; Biris, A.R.; Lupu, D.; Biris, A.S. Surface area and thermal stability effect of the $\mathrm{MgO}$ supported catalysts for the synthesis of carbon nanotubes. J. Mater. Chem 2008, 18, 5738-5745.

135. Wang, G.; Wang, H.; Tang, Z.X.; Li, W.L.; Bai, J.B. Simultaneous production of hydrogen and multi-walled carbon nanotubes by ethanol decomposition over $\mathrm{Ni} / \mathrm{Al}_{2} \mathrm{O}_{3}$ catalysts. Appl. Catal. B-Environ 2009, 88, 142-151.

136. Wang, X.Q.; Li, L.; Chu, N.J.; Liu, Y.P.; In, H.X.; Ge, H.L. Lamellar Fe $/ \mathrm{Al}_{2} \mathrm{O}_{3}$ catalyst for high-yield production of multi-walled carbon nanotubes bundles. Mater. Res. Bull. 2009, 44, $422-425$.

137. Li, C.H.; Zhao, Y.; Yao, K.F.; Liang, J. Application of carbon nanotube supported nickel/aluminum mixed oxide in the synthesis of carbon nanotubes. Carbon 2003, 41, 2443-2446.

138. Liu, Y; Shen, Z. Preparation of carbon microcoils and nanocoils using activated carbon nanotubes as catalyst support. Carbon 2005, 43, 1574-1577.

139. Changa, N.K.; Changa, S.H. High-yield synthesis of carbon nanocoils on stainless steel. Carbon 2008, 46, 1091-1109. 
140. Masarapu, C.; Wei, B.Q. Direct growth of aligned multiwalled carbon nanotubes on treated stainless steel substrates. Langmuir 2007, 23, 9046-9049.

141. Yu, G.J.; Gong, J.L.; Zhu, D.Z.; He, S.X.; Zhu, Z.Y. Synthesis of carbon nanotubes over rare earth zeolites at low temperature. Carbon 2005, 43, 3015-3017.

142. Hiraoka, T.; Kawakubo, T.; Kimura, J.; Taniguchi, R.; Okamoto, A.; Okazaki, T.; Sugai, T.; Ozeki, Y.; Yoshikawa, M.; Shinohara, H. Selective synthesis of double-wall carbon nanotubes by CCVD of acetylene using zeolite supports. Chem. Phys. Lett. 2003, 382, 679-685.

143. Hsieh, C.T.; Lin, Y.T.; Lin, J.Y.; Wei, J.L. Synthesis of carbon nanotubes over Ni- and Co-supported $\mathrm{CaCO}_{3}$ catalysts using catalytic chemical vapor deposition. Mater. Chem. Phys. 2009, 114, 702-708.

144. Zhang, M.; Nakayama, Y.; Pan, L.J. Synthesis of carbon tubule nanocoils in high yield using iron-coated indium tin oxide as catalyst. Jpn. J. Appl. Phys. 2000, 39, L1242-L1244.

145. Vander Wal, R.L.; Ticich, T.M.; Curtis, V.E. Substrate-support interactions in metal-catalyzed carbon nanofiber growth. Carbon 2001, 39, 2277-2289.

146. Ortega-Cervantez, G.; Rueda-Morales, G.; Ortiz-Lopez, J. Catalytic CVD production of carbon nanotubes using ethanol. Microelectron. J. 2005, 36, 495-498.

147. Zhu, J.; Yudasaka, M.; Iijima, S. A catalytic chemical vapor deposition synthesis of double-walled carbon nanotubes over metal catalysts supported on a mesoporous material. Chem. Phys. Lett. 2003, 380, 496-502.

148. Qi, X.S.; Deng, Y.; Zhong, W.; Yang, Y.; Qin, C.; Au, C.T.; Du, Y.W. Controllable and large-scale synthesis of carbon nanofibers, bamboo-like nanotubes and chains of nanospheres over $\mathrm{Fe} / \mathrm{SnO}_{2}$, and their microwave absorption properties. J. Phys. Chem. C 2010, 114, 808-814.

149. Colomer, J.F.; Piedigrosso, P.; Willems, I.; Journet, C.; Bernier, P.; Van Tendeloo, G.; Fonseca, A.; Nagy, J.B. Purification of catalytically produced multi-wall nanotubes. J. Chem. Soc. Faraday Trans. 1998, 94, 3753-3758.

150. Bian, J.; Xiao, M.; Wang, S.J.; Lu, Y.X.; Meng, Y.Z. Carbon nanotubes supported Cu-Ni bimetallic catalysts and their properties for the direct synthesis of dimethyl carbonate from methanol and carbon dioxide. Appl. Surf. Sci. 2009, 255, 7188-7196.

151. Chen, B.; Wu, P. Aligned carbon nanotubes by catalytic decomposition of $\mathrm{C}_{2} \mathrm{H}_{2}$ over Ni-Cr alloy. Carbon 2005, 43, 3172-3177.

152. Hu, J.L.; Yang, C.C.; Huang, J.H. Vertically-aligned carbon nanotubes prepared by water-assisted chemical vapor deposition. Diamond Relat. Mater. 2008, 17, 2084-2088.

153. Wang, W.; Yang, K.Q.; Gaillard, J.; Bandaru, P.R.; Rao, A.M. Rational synthesis of helically coiled carbon nanowires and nanotubes through the use of tin and indium catalysts. Adv. Mater. 2008, 20, 179-182.

154. Rodriguez, N.M. A review of catalytically growth carbon nanofibers. J. Mater. Res. 1993, 8, 3233-3250.

155. Li, Y.D.; Chen, J.L.; Ma, Y.M.; Zhao, J.B.; Qin, Y.N. Chang, L. Formation of bamboo-like nanocarbon and evidence for the quasi-liquid state of nanosized metal particles at moderate temperatures. Chem. Commun. 1999, 12, 1141-1142. 
156. Chambers, A.; Rodriguez, N.M.; Baker, R.T.K. Influence of copper on the structural characteristics of carbon nanofibers produced from the cobalt-catalyzed decomposition of ethylene. J. Mater. Res. 1996, 11, 430-438.

157. Chen, B.; Wu, P. Aligned carbon nanotubes by catalytic decomposition of $\mathrm{C}_{2} \mathrm{H}_{2}$ over Ni-Cr alloy. Carbon 2005, 43, 3172-3177.

158. Topsoe, H.; Clausen, B.S.; Candia, R.; Wivel, C.; Morup, S. Insitu Mossbauer emission-spectroscopy studies of unsupported and supported sulfided Co-Mo hydrodesulfurization catalysts - evidence for and nature of a Co-Mo-S phase. J. Catal. 1981, 68, 433-452.

159. Okamoto, Y.; Kubota, T. A model catalyst approach to the effects of the support on Co-Mo hydrodesulfurization catalysts. Catal. Today 2003, 86, 31-43.

160. Kitiyanan, B.; Alvarez, W.E.; Harwell, J.H.; Resasco, D.E. Controlled production of single-wall carbon nanotubes by catalytic decomposition of $\mathrm{CO}$ on bimetallic Co-Mo catalysts. Chem. Phys. Lett. 2000, 317, 497-503.

161. Ago, H.; Ohshima, S.; Uchida, K.; Yumura, M. Gas-phase synthesis of single-wall carbon nanotubes from colloidal solution of metal nanoparticles. J. Phys. Chem. B 2001, 105, 10453-10456.

162. Yoon, Y.J.; Bae, J.C.; Baik, H.K.; Cho, S.J.; Lee, S.; Song, K.M.; Myung, N.S. Nucleation and growth control of carbon nanotubes in CVD process. Phys. B 2002, 323, 318-320.

163. Alvarez, W.E.; Pompeo, F.; Herrera, J.E.; Balzano, L.; Resasco, D.E. Characterization of single-walled carbon nanotubes (SWNTs) produced by $\mathrm{CO}$ disproportionation on Co-Mo catalysts. Chem. Mater. 2002, 14, 1853-1858.

164. Maruyama, S.; Kojima, R.; Miyauchi, Y.; Chiashi, S.; Kohno, M. Low-temperature synthesis of high-purity single-walled carbon nanotubes from alcohol. Chem. Phys. Lett. 2002, 360, 229-234.

165. Murakami, Y.; Miyauchi, Y.; Chiashi, S.; Maruyama, S. Direct synthesis of high-quality single-walled carbon nanotubes on silicon and quartz substrates. Chem. Phys. Lett. 2003, 377, 49-54.

166. Murakami, Y.; Chiashi, S.; Miyauchi, Y.; Hu, M.; Ogura, M.; Okubo, T.; Maruyama, S. Growth of vertically aligned single-walled carbon nanotube films on quartz substrates and their optical anisotropy. Chem. Phys. Lett. 2004, 385, 298-303.

167. Murakami, Y.; Chiashi, S.; Miyauchi, Y.; Maruyama, S. Direct synthesis of single-walled carbon nanotubes on silicon and quartz-based systems. Jpn. J. Appl. Phys. 2004, 43, 1221-1126.

168. Herrera, J.E.; Balzano, L.; Borgna, A.; Alvarez, W.E.; Resasco, D.E. Relationship between the structure/composition of Co-Mo catalysts and their ability to produce single-walled carbon nanotubes by CO disproportionation. J. Catal. 2001, 204, 129-145.

169. Alvarez, W.E.; Kitiyanan, B.; Borgna, A.; Resasco, D.E. Synergism of Co and Mo in the catalytic production of single-wall carbon nanotubes by decomposition of CO. Carbon 2001, 39, $547-548$.

170. Resasco, D.E.; Alvarez, W.E.; Pompeo, F.; Balzano, L.; Herrera, J.E.; Kitiyanan, B.; Borgna, A. A scalable process for production of single-walled carbon nanotubes (SWNTs) by catalytic disproportionation of CO on a solid catalyst. J. Nanopart. Res. 2002, 4, 131-136. 
171. Herrera, J.E.; Resasco, D.E. Loss of single-walled carbon nanotubes selectivity by disruption of the Co-Mo interaction in the catalyst. J. Catal. 2004, 221, 354-364.

172. Kitiyanan. B.; Alvarez, W.E.; Harwell, J.H.; Resasco, D.E. Controlled production of single-wall carbon nanotubes by catalytic decomposition of $\mathrm{CO}$ on bimetallic Co-Mo catalysts. Chem. Phys. Lett. 2000, 317, 497-503.

173. Okazaki, N.; Hosokawa, S.; Goto, T.; Nakayama, Y. Synthesis of carbon tubule nanocoils using Fe-In-Sn-O fine particles as catalysts. J. Phys. Chem. B 2005, 109, 17366-17371.

174. Pan, L.J.; Hayashida, T.; Harada, A.; Nakayama, Y. Effects of iron and indium tin oxide on the growth of carbon tubule nanocoils. Phys. B 2002, 323, 350-351.

175. Qi, X.S.; Zhong, W.; Deng, Y.; Au, C.T.; Du, Y.W. Characterization and magnetic properties of helical carbon nanotubes and carbon nanobelts synthesized in acetylene decomposition over $\mathrm{Fe}-\mathrm{Cu}$ nanoparticles at $450{ }^{\circ} \mathrm{C}$. J. Phys. Chem. C 2009, 113, 15934-15940.

176. Donato, M.G.; Galvagno, S.; Lanza, M.; Messina, G.; Milone, C.; Piperopoulos, E.; Pistone, A.; Santangelo, S. Influence of carbon source and Fe-catalyst support on the growth of multi-walled carbon nanotubes. J. Nanosci. Nanotechno. 2009, 9, 3815-3823.

177. Nourbakhsh, A.; Ganjipour, B.; Zahedifar, M.; Arzi, E. Morphology optimization of CCVD-synthesized multiwall carbon nanotubes, using statistical design of experiments. Nanotechnology 2007, 18, 115715.

178. Signore, M.A.; Rizzo, A.; Rossi, R.; Piscopiello, E.; Di Luccio, T.; Capodieci, L.; Dikonimos, T.; Giorgi, R. Role of iron catalyst particles density in the growth of forest-like carbon nanotubes. Diamond Relat. Mater. 2008, 17, 1936-1942.

179. Vander Wal, R.L.; Hall, L.J.; Berger, G.M. Optimization of flame synthesis for carbon nanotubes using supported catalyst. J. Phys. Chem. B 2002, 106, 13122-13132.

180. Piao, L.Y.; Li, Y.D.; Chen, J.L.; Chang, L.; Lin, J.Y.S. Methane decomposition to carbon nanotubes and hydrogen on an alumina supported nickel aerogel catalyst. Catal. Today 2002, 74, $145-155$.

181. Chai, S.P.; Zein, S.H.S.; Mohamed, A.R. The effect of reduction temperature on $\mathrm{Co}-\mathrm{Mo} / \mathrm{Al}_{2} \mathrm{O}_{3}$ catalysts for carbon nanotubes formation. Appl. Catal. A-Gen 2007, 326, 173-179.

182. Chen, X.Q.; Motojima, S. The growth patterns and morphologies of carbon micro-coils produced by chemical vapor deposition. Carbon 1999, 37, 1817-1823.

183. Chen, X..Q.; Yang, S. M.; Kato, Y.; Motojima, S. Influence of CVD conditions on the growth of carbon microcoils with circular cross-sections. Mater. Lett. 2007, 61, 2900-2903.

184. Qi, X.S.; Yang, Y.; Zhong, W.; Deng, Y.; Au, C.T.; Du. Y.W. Large-scale synthesis, characterization and microwave absorption properties of carbon nanotubes of different helicities. J Solid State Chem 2009, 182, 2691-2697.

185. Messina, G.; Santangelo, S.; Donato, M.G.; Lanza, M.; Milone, C.; Pistone, A.; Galvagno, S. Multi-walled carbon nanotubes production by ethane decomposition over silica-supported iron-catalysts. Phys. Status. Solidi. A 2008, 205, 2422-2427.

186. Liu, Y.F.; Shen, Z.M. Preparation of carbon microcoils and nanocoils using activated carbon nanotubes as catalyst support. Carbon 2005, 43, 1557-158. 
187. Xu, G.C.; Chen, B.B.; Shiki, H.; Katsumata, T.; Takikawa, H.; Sakakibara, T.; Itoh, S.; Ina, T.; Parametric study on growth of carbon nanocoil by catalytic chemical vapor deposition. Jpn. J. Appl. Phys. 2005, 44, 1569-1576.

188. Xi, G.C.; Zhang, M.; Ma, D.K.; Zhu, Y.C.; Zhang, H.B.; Qian, Y.T. Controlled synthesis of carbon nanocables and branched-nanobelts. Carbon 2006, 44, 734-741

189. Borowiak-Palen, E.; Rümmeli, M.H. Activated $\mathrm{Cu}$ catalysts for alcohol CVD synthesized non-magnetic bamboo-like carbon nanotubes and branched bamboo-like carbon nanotubes. Superlattice Microst 2009, 46, 374-378.

190. Li, H.P.; Shi, C.S.; Du, X.W.; He, C.N.; Li, J.J.; Zhao, N.Q. The influences of synthesis temperature and $\mathrm{Ni}$ catalyst on the growth of carbon nanotubes by chemical vapor deposition. Mater. Lett. 2008, 62, 1472-1475.

191. Singh, C.; Shaffer, M.S.; Windle, A.H. Production of controlled architectures of aligned carbon nanotubes by an injection chemical vapor deposition method. Carbon 2003, 41, 359-368.

192. Qi, X.S.; Xu, M.H.; Zhong, W.; Ye, X.J.; Deng, Y.; Au, C.T.; Jin, C.Q.; Du, Y.W. Magnetic properties and large-scale synthesis of novel carbon nanocomposites via benzene decomposition over Ni nanoparticles J. Phys. Chem. C 2009, 113, 2267-2272.

193. Jin, Y.Z.; Gao, C.; Hsu, W.K.; Zhu, Y.Q.; Huczko, A.; Bystrzejewski, M.; Roe, M.; Lee, C.Y.; Acquah, S.; Kroto, H.; Walton, D.R.M. Large-scale synthesis and characterization of carbon spheres prepared by direct pyrolysis of hydrocarbons. Carbon 2005, 43, 1944-1953.

194. Yamada, M.; Kawana, M.; Miyake, M. Synthesis and diameter control of multi-walled carbon nanotubes over gold nanoparticle catalysts. Appl. Catal. A-Gen 2006, 302, 201-207.

195. Yang, S.M.; Ozeki, I.; Chen, X.Q.; Katsuno, T.; Motojima, S. Preparation of single-helix carbon microcoils by catalytic CVD process. Thin Solid Films 2008, 516, 718-721.

196. Chen, X.Q.; Hasegawa, M.; Yang, S.M.; Nitta, Y.; Katsuno, T.; Motojima, S. Preparation of carbon microcoils by catalytic methane hot-wire CVD process. Thin Solid Films 2008, 516, 714-717.

197. Chen, Y.; Liu, C.; Du, J.H.; Cheng, H.M. Preparation of carbon microcoils by catalytic decomposition of acetylene using nickel foam as both catalyst and substrate Carbon 2005, 43, 1874-1878.

198. Li, Q.; Yan, H.; Zhang, J.; Liu, Z. Effect of hydrocarbons precursors on the formation of carbon nanotubes in chemical vapor deposition. Carbon 2004, 42, 829-835.

199. Lv, R.; Kang, F.Y.; Wang, W.X.; Wei, J.Q.; Gu, J.L.; Wang, K.L.; Wu, D.H. Effect of using chlorine-containing precursors in the synthesis of FeNi-filled carbon nanotubes. Carbon 2007, 45, $1433-1438$.

200. Motojima, S.; Hasegawa, I.; Kaziya, S.; Momiyama, M.; Kawaguch, M.; Iwanaga, H. Preparation of coiled carbon fibers by pyrolysis of acetylene using a Ni catalyst and sulfur or phosphrous compounds impurity. Appl. Phys. Lett. 1993, 62, 2322-2323.

201. Iwanaga, H.; Kawaguchi, M.; Motojima, S. Growth mechanisms and properties of coiled whiskers of silicon nitride and carbon. Jpn. J. Appl. Phys. 1993, 32, 105-115.

202. Zhao, D.L.; Shen, Z.M. Preparation and microwave absorption properties of carbon nanocoils. Mater. Lett. 2008, 62, 3704-3706. 
203. Chen, X.; Yang, S.; Takeuchi, K.; Hashishin, T.; Iwanaga, H.; Motojima, S. Conformation and growth mechanism of the carbon nanocoils with twisting form in comparison with that of carbon microcoils. Diamond Relat. Mater. 2003, 12, 1836-1840.

204. Motojima, S.; Chen, X.; Yang, S.; Hasegawa, M. Properties and potential applications of carbon microcoils/nanocoils. Diamond Relat. Mater. 2004, 13, 1989-1992.

(C) 2010 by the authors; licensee MDPI, Basel, Switzerland. This article is an Open Access article distributed under the terms and conditions of the Creative Commons Attribution license (http://creativecommons.org/licenses/by/3.0/). 